\title{
Review Article \\ Pathophysiologic Mechanisms of Cardiovascular Disease in Obstructive Sleep Apnea Syndrome
}

\author{
Carlos Zamarrón, ${ }^{1}$ Luis Valdés Cuadrado, ${ }^{1}$ and Rodolfo Álvarez-Sala ${ }^{2}$ \\ ${ }^{1}$ Division of Respiratory, Hospital Clínico Universitario, c/Travesia de la Choupana s/n, A Coruña, 15706 Santiago, Spain \\ ${ }^{2}$ Division of Respiratory, Hospital Universitario La Paz, Paseo de la Castellana 261, 28046 Madrid, Spain \\ Correspondence should be addressed to Luis Valdés Cuadrado; luis.valdes.cuadrado@sergas.es
}

Received 28 February 2013; Accepted 24 April 2013

Academic Editor: Francisco García Río

Copyright (c) 2013 Carlos Zamarrón et al. This is an open access article distributed under the Creative Commons Attribution License, which permits unrestricted use, distribution, and reproduction in any medium, provided the original work is properly cited.

\begin{abstract}
Obstructive sleep apnea syndrome (OSAS) is a highly prevalent sleep disorder, characterized by repeated disruptions of breathing during sleep. This disease has many potential consequences including excessive daytime sleepiness, neurocognitive deterioration, endocrinologic and metabolic effects, and decreased quality of life. Patients with OSAS experience repetitive episodes of hypoxia and reoxygenation during transient cessation of breathing that provoke systemic effects. Furthermore, there may be increased levels of biomarkers linked to endocrine-metabolic and cardiovascular alterations. Epidemiological studies have identified OSAS as an independent comorbid factor in cardiovascular and cerebrovascular diseases, and physiopathological links may exist with onset and progression of heart failure. In addition, OSAS is associated with other disorders and comorbidities which worsen cardiovascular consequences, such as obesity, diabetes, and metabolic syndrome. Metabolic syndrome is an emerging public health problem that represents a constellation of cardiovascular risk factors. Both OSAS and metabolic syndrome may exert negative synergistic effects on the cardiovascular system through multiple mechanisms (e.g., hypoxemia, sleep disruption, activation of the sympathetic nervous system, and inflammatory activation). It has been found that CPAP therapy for OSAS provides an objective improvement in symptoms and cardiac function, decreases cardiovascular risk, improves insulin sensitivity, and normalises biomarkers. OSAS contributes to the pathogenesis of cardiovascular disease independently and by interaction with comorbidities. The present review focuses on indirect and direct evidence regarding mechanisms implicated in cardiovascular disease among OSAS patients.
\end{abstract}

\section{Introduction}

Obstructive sleep apnea syndrome (OSAS) is a common disorder characterized by recurrent upper airway collapse during sleep [1]. This results in a reduction or complete cessation of airflow despite ongoing inspiratory efforts and leads to arousals, sleep fragmentation, and oxyhemoglobin desaturation [2].

A spectrum of sleep related obstructed breathing has been described in the literature [3]. This ranges from snoring [4], and upper airway resistance syndrome [5] to obesity hypoventilation syndrome [6]. The focus of the current review is OSAS, which lies in between these two extremes.

Though clinically recognized since the 1960s [7], general awareness of OSAS has been slow to develop. OSAS has been associated with cardiovascular disease [8], automobile accidents [9], chronic obstructive pulmonary disease (COPD) [10], heart failure [11] and health related quality of life deterioration [12].

Another emerging public health problem is metabolic syndrome, which represents a constellation of cardiovascular risk factors. OSAS often coexists with obesity and has been shown to be independently associated with insulin resistance, which is an important component of metabolic syndrome $[1,13]$. Given the current obesity epidemic, the prevalence of both metabolic syndrome and OSAS is on the rise.

The present review analyzes the relation between OSAS and cardiovascular disease and how it may be affected by OSAS-associated disorders and comorbidities. 
TABLE 1: Prevalence studies on obstructive sleep apnea syndrome.

\begin{tabular}{|c|c|c|c|c|c|c|}
\hline Study & Population & Age & Method & Criteria & SDB prevalence & OSAS \\
\hline \multirow{6}{*}{$\begin{array}{l}\text { Durán et al. } \\
2001[14]\end{array}$} & \multirow{6}{*}{$\begin{array}{l}2148 \text { subjects } \\
\text { from the electoral } \\
\text { census }\end{array}$} & \multirow{6}{*}{$30-70$} & \multirow{6}{*}{$\begin{array}{l}\text { (1) Questionnaire } \\
\text { (2) Validated portable } \\
\text { instrument in } 442 \text { subjects } \\
\text { (3) PSG in } 555 \text { subjects }\end{array}$} & $\mathrm{AHI} \geq 5$ & $26.3 \%(\mathrm{M})$ and $28 \%(\mathrm{~F})$ & \\
\hline & & & & $\mathrm{AHI} \geq 10$ & $19 \%(\mathrm{M})$ and $14.9 \%(\mathrm{~F})$ & \\
\hline & & & & $\mathrm{AHI} \geq 15$ & $14.2 \%(\mathrm{M})$ and $8.6 \%(\mathrm{~F})$ & \\
\hline & & & & $\mathrm{AHI} \geq 20$ & $9.6 \%(\mathrm{M})$ and $6 \%(\mathrm{~F})$ & \\
\hline & & & & $\mathrm{AHI} \geq 30$ & $6.8 \%(\mathrm{M})$ and $4.3 \%(\mathrm{~F})$ & \\
\hline & & & & $\begin{array}{l}\text { OSAS }=\text { AHI } \geq 10 \text { plus } \\
\text { Symptoms }\end{array}$ & & $\begin{array}{c}3.4 \% \mathrm{M} \\
3 \% \mathrm{~F}\end{array}$ \\
\hline \multirow{4}{*}{$\begin{array}{l}\text { Udwadia et al., } \\
2004 \text { [15] }\end{array}$} & \multirow{4}{*}{$\begin{array}{l}658 \text { healthy urban } \\
\text { Indian subjects }\end{array}$} & \multirow{4}{*}{$35-65$} & \multirow{4}{*}{$\begin{array}{l}\text { (1) Questionnaire } \\
\text { (2) PSG on subgroup in } 250 \\
\text { subjects }\end{array}$} & $\mathrm{AHI} \geq 5$ & $19.5 \%$ & $7.5 \%$ \\
\hline & & & & $\mathrm{AHI} \geq 10$ & $11.1 \%$ & $6.1 \%$ \\
\hline & & & & $\mathrm{AHI} \geq 15$ & $8.4 \%$ & $5.4 \%$ \\
\hline & & & & $\begin{array}{l}\text { OSAS = AHI plus } \\
\text { Symptoms }\end{array}$ & & \\
\hline \multirow{2}{*}{$\begin{array}{l}\text { Sharma et al., } \\
2006 \text { [16] }\end{array}$} & \multirow{2}{*}{$\begin{array}{l}2150 \text { semiurban } \\
\text { community in } \\
\text { Delhi }\end{array}$} & \multirow[b]{2}{*}{$30-60$} & \multirow{2}{*}{$\begin{array}{l}\text { (1) Questionnaire } \\
\text { (2) PSG on subgroup in } 150 \\
\text { subjects }\end{array}$} & $\mathrm{AHI} \geq 5$ & $13.7 \%$ & \\
\hline & & & & $\begin{array}{l}\text { OSAS }=\text { AHI } \geq 5 \text { plus } \\
\text { Symptoms }\end{array}$ & & $3.6 \%$ \\
\hline \multirow{2}{*}{$\begin{array}{l}\text { Pływaczewski } \\
\text { et al., } 2008 \\
{[17]}\end{array}$} & \multirow{2}{*}{$\begin{array}{l}1503 \text { from } \\
\text { Warsaw electoral } \\
\text { registers }\end{array}$} & \multirow{2}{*}{$\begin{array}{l}\text { Over } 30 \\
\text { years of } \\
\text { age }\end{array}$} & \multirow{2}{*}{$\begin{array}{l}\text { (1) Questionnaire } \\
\text { (2) PSG on subgroup in } 676 \\
\text { subjects }\end{array}$} & $\mathrm{AHI} \geq 10$ & $14.3 \%$ & \\
\hline & & & & $\begin{array}{l}\text { OSAS }=\text { AHI } \geq 10 \text { plus } \\
\text { Symptoms }\end{array}$ & & $7.5 \%$ \\
\hline
\end{tabular}

Abbreviations: AHI: apnea hypopnea index; PSG: polysomnography; SDB: sleep disordered breathing; M: male; F: female.

\section{OSAS Epidemiology}

A variety of epidemiological studies have demonstrated the high prevalence of OSAS and its relation to cardiovascular risk factors (Table 1). Durán et al. in 2001, performed 555 complete polysomnographies and found sleep disordered breathing, defined as AHI > 5, in $26.3 \%$ of men and $28 \%$ of women. AHI was associated with hypertension after adjusting for age, sex, BMI, neck circumference, alcohol use, and smoking habit [14]. In India, Udwadia et al. found a $19.5 \%$ prevalence of sleep disordered breathing, defined as AHI > 5, and 7.5\% prevalence of OSAS, defined as AHI $>5$ with symptoms. BMI, neck circumference and diabetes mellitus were found to be associated with sleep disordered breathing [15]. Sharma et al. reported a $13.7 \%$ overall prevalence of sleep disordered breathing and 3.6\% prevalence of OSAS. Multivariate analysis revealed that male gender, age, obesity, and waist/hip ratio were significant risk factors for OSAS [16].

Pływaczewski et al. found a 7.5\% prevalence of OSAS. OSAS was found to be an independent predictor of coronary artery disease after adjusting for age, sex, BMI, neck circumference, and smoking habit [17].

As age advances, sleep breathing related difficulties become increasingly common. Several OSAS studies in older populations report little or no association of OSAS with sleepiness, hypertension, or decrements in cognitive function $[18,19]$.

\section{OSAS and Cardiovascular Diseases Mechanisms}

The mechanisms involved in the association between OSAS and vascular diseases are complex and diverse. Patients with OSAS experience repetitive episodes of hypoxia and reoxygenation during transient cessation of breathing that may provoke systemic effects. These patients also present increased levels of biomarkers linked to endocrine-metabolic and cardiovascular alterations. The relation between OSAS and cardiovascular disease involves a number of mechanisms such as the following (Figure 1).

3.1. Sleep Fragmentation. The importance of sleep to health and cardiovascular disease has become increasingly apparent. Percentage time in slow wave sleep has been inversely associated with incident hypertension (regardless of sleep duration and fragmentation) and sleep-disordered breathing. In fact, selective deprivation of slow wave sleep may contribute to adverse blood pressure in older men [20]. Bekci et al. found that total antioxidant capacities were decreased in the higher arousal index, suggesting that patients with higher arousal index may be more prone to vascular events [21].

In OSAS, severe sleep fragmentation disturbs nocturnal renin and aldosterone secretion profiles and increases nighttime urine excretion. CPAP treatment has been reported to improve sleep, restore plasma renin activity and aldosterone oscillations, and lower nocturnal urine natriuresis and diuresis [22]. Møller et al. found that long-term CPAP (Continuous positive airway pressure) reduced blood pressure, which was correlated with reductions in plasma renin and angiotensin II levels [23].

Extreme sleep habits can affect health and have been associated with increased inflammation. Significant changes in habitual sleep duration can lead to chronic low-grade systemic inflammation [24] and activation of proinflammatory pathways may represent a mechanism. In a study involving 


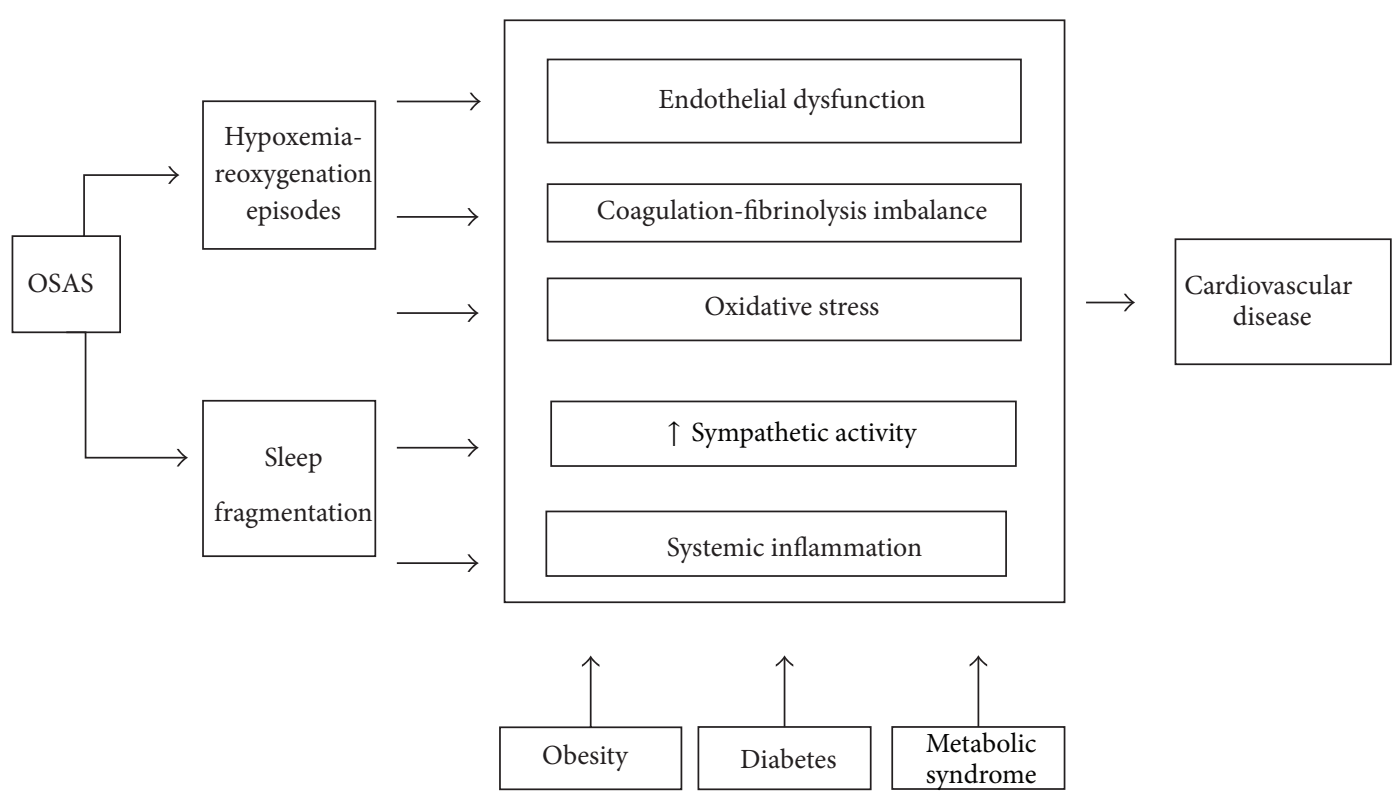

FIGURE 1: A schematic summary of the proposed sequence of events in obstructive sleep apnea syndrome starting from episodic hypoxia and sleep fragmentation.

pediatric OSAS patients, increased TNF- $\alpha$ levels were primarily driven by sleep fragmentation and BMI. These levels were closely associated with the degree of sleepiness. Surgical treatment of OSAS resulted in significant reductions in TNF$\alpha$ levels and reduction in sleepiness [25].

3.2. Enhanced Sympathetic Traffic. In OSAS, there is enhanced sympathetic traffic through a tonic activation of chemoreflex activity that normalizes with CPAP treatment $[26,27]$. OSAS-associated disturbances, especially chronic intermittent hypoxia and enhanced sympathetic activity, lead to upregulation of the renin-angiotensin system and downregulation of nitric oxide synthases [28]. When an obstructive apnea occurs, it is terminated by a sudden arousal, that is, lightening of sleep or awakening from sleep [29]. The cyclic intermittent hypoxia provides the causal link between upper airway obstruction during sleep and sympathetic activation during awakening. Cyclic intermittent hypoxia may lead to sympathoexcitation via two mechanisms: first, augmentation of peripheral chemoreflex sensitivity (hypoxic acclimatization) and, second, direct effects on sites of central sympathetic regulation.

In a study in healthy humans, intermittent hypoxia significantly increased sympathetic activity and daytime blood pressure after a single night of exposure. The baroreflex control of sympathetic outflow declined [30]. Surges in sympathetic nervous system activity associated with apneic events have also been related to antifibrinolytic activity reflected by elevations in PAI-1 [31].

Increased sympathetic activity and intermittent hypoxia associated with apneic episodes has been proposed as a possible mechanism behind the association between OSAS, systemic inflammation and cardiovascular disease. CPAP reduces sympathetic nerve activity [32], increases arterial baroreflex sensitivity [33], and decreases vascular risk [34].

3.3. Oxidative Stress. In OSAS patients, increased production of superoxide by neutrophils [35], increased biomarkers of lipid peroxidation [36], and increased levels of 8-isoprostanes [37] have been observed. There is an emerging consensus that OSAS is an oxidative stress disorder.

Apnea produces a decline in oxygen levels followed by reoxygenation when breathing resumes. Cyclical episodes of hypoxia-reoxygenation, which are analogous to cardiac ischemia/reoxygenation injury, may cause ATP depletion and xanthine oxidase activation and increases the generation of oxygen-derived free radicals. CPAP therapy decreases the levels of oxidative stress in OSAS patients [38,39].

In a study involving children with OSAS, Malakasioti et al. found increased hydrogen peroxide levels in exhaled breath condensate, which is an indirect index of altered redox status in the respiratory tract [40].

Oxidative stress can profoundly regulate the cellular transcriptome through activation of transcription factors, including specificity protein-1, hypoxia-inducible factor-1, c-jun, and possibly $\mathrm{NF} \kappa \beta$. Activation of redox-sensitive gene expression is suggested by the increase in some protein products of these genes, including vascular endothelial growth factor [41], erythropoietin [42], and endothelin-1 [43]. Low oxygen tension is a trigger for activation of polymorphonuclear neutrophils, which adhere to the endothelium [44].

Increased oxidative stress has been associated with development of cardiovascular diseases and can be promoted by the chronic intermittent hypoxia characteristic of OSAS [45]. A variety of studies suggest that oxidative stress is present in OSAS at levels relevant to tissues such as the arterial wall $[46,47]$. This process enhances lipid uptake into human 
macrophages and may contribute to atherosclerosis in OSAS patients [48]. Furthermore, OSAS decreases blood antioxidant status in high-BMI subjects and may change the relationship between oxidative stress markers [49]. After CPAP, expression of eNOS and phosphorylated eNOS was found to be significantly increased, whereas expression of nitrotyrosine and nuclear factor-kappaB was significantly decreased [50]. However, other studies have shown that CPAP may not affect antioxidant defense [51]. Nair reported that oxidative stress is mediated, at least in part, by excessive NADPH oxidase activity. This author suggests that pharmacological agents targeting NADPH oxidase may provide a therapeutic strategy in OSAS [52].

3.4. Systemic Inflammation. In OSAS, intense local and systemic inflammations are present. Insofar as local inflammation, bronchial and nasal changes are especially relevant [53]. In a study by Carpagnano et al., OSAS patients showed a significant increase in IL-8 and ICAM concentrations in both plasma and exhaled condensate. In addition, they showed a higher neutrophil percentage in induced sputum. These findings were significantly and positively correlated to AHI [54]. In a recent study of 80 nonsmoking males, Cofta et al., found a progressive increase in the concentrations of three selectins with the severity of OSAS [55].

Adhesion of circulating leukocytes to the endothelial cells is considered one of the initial steps in the pathogenesis of atherosclerosis. The repetitive hypoxia-reoxygenation episodes associated with apneas and hypopneas in OSAS upregulate the production of inflammatory mediators and the expression of adhesion molecules. Different studies have reported changes in circulating levels of adhesion molecules in OSAS patients $[56,57]$. Dyugovskaya et al. analysed polymorphonuclear apoptosis and expression of adhesion molecules in vitro in patients with moderate to severe OSAS. Decreased apoptosis and increased expression of adhesion molecules were observed. Although adhesion molecules may facilitate increased polymorphonuclear-endothelium interactions, decreased apoptosis may further augment these interactions and facilitate free radical and proteolytic enzymes [58].

OSAS patients present increased levels of inflammatory mediators such as TNF $\alpha$ and IL-6 $[59,60]$ that decrease with CPAP treatment $[61,62]$.

Systemic inflammation is increasingly being recognized as a risk factor for a number of complications including atherosclerosis [63] and is a well-established factor in the pathogenesis of cardiovascular disease [64]. Serum amyloid $\mathrm{A}$ is a major acute-phase protein in humans that has been associated with cardiovascular disease [65]. Levels of this protein are chronically elevated in patients with OSAS [66] and improve with CPAP [67].

C-reactive protein is an important serum marker of inflammation with major implications for cardiovascular morbidity and atherogenesis [68]. C-reactive protein levels are increased in OSAS in accordance with disease severity [69-71] and are decreased after CPAP treatment $[72,73]$.

The mechanisms by which inflammation contributes to OSAS-induced vascular dysfunction are not known.
Reoxygenation after a brief period of hypoxia as experienced repetitively and systematically by OSAS patients may predispose to cell stress, possibly because of mitochondrial dysfunction. It has been suggested that such events favor the activation of a proinflammatory response as mediated through the transcription factor nuclear $\mathrm{NF} \kappa \beta$, a master regulator of inflammatory gene expression. The downstream effects of this activation include increased expression of inflammatory cytokines which may contribute to endothelial dysfunction and subsequently cardiovascular complications [74].

Inflammation may be an important link between increased sympathetic nervous system activity and vascular dysfunction in OSAS. Chronically elevated sympathetic activity produced an inflammatory response in several organs and vascular beds [75].

Some authors point to the role of the T lymphocyte. This cell is known to play an important role in angiotensin II-induced hypertension and endothelial dysfunction via NADPH oxidase-induced superoxide production [76].

Increased expression of inflammatory cytokines may contribute to endothelial dysfunction and subsequent cardiovascular complications. Currently, some studies suggest that pentraxin 3 , an acute phase response protein, is rapidly produced and released by several cell types, especially mononuclear phagocytes and endothelial cells in response to primary inflammatory signals. Pentraxin 3 may play a significant role in OSAS-associated vascular damage [77]. Arnaud et al. reported that some inhibition of molecules such as RANTES/CCL5, a cytokine that selectively attracts memory T lymphocytes and monocytes, may play a significant role in athesrosclerosis remodeling and OSAS-associated vascular damage [78].

However, mesenchymal stem cells triggered an early anti-inflammatory response in rats subjected to recurrent obstructive apneas, suggesting that these stem cells could play a role in the physiological response to counterbalance inflammation in OSAS [79].

In healthy human males, Querido et al. analysed the effect over 10 days of nightly intermittent hypoxia in the following systemic inflammatory markers: serum granulocyte macrophage colony-stimulating factor, interferon- $\gamma$, interleukin $1 \beta$, interleukin 6 , interleukin 8 , leptin, monocyte chemotactic protein-1, vascular endothelial growth factor, intracellular adhesion molecule-1, and vascular cell adhesion molecule-1. There was no significant change in any of the markers. These findings suggest that a more substantial or a different pattern of hypoxemia might be necessary to activate systemic inflammation, that the system may need to be primed before hypoxic exposure, or that increases in inflammatory markers in OSAS patients may be more related to other factors such as obesity or nocturnal arousal [80].

3.5. Hypercoagulability. Hypercoagulability resulting from increased coagulation or inhibited fibrinolysis is associated with an increased risk for cardiovascular disease [81, 82]. This is another factor implicated in its association with OSAS $[83,84]$. 
A variety of findings support the existence of a relation between hypercoagulability, OSAS, and cardiovascular disease. Firstly, patients with OSAS present higher plasma levels of several procoagulant factors such as fibrinogen [85], activated clotting factor FVII (FVIIa), FXIIa, and thrombin/antithrombin III complexes [86], platelet activity [87], and the fibrinolysis-inhibiting enzyme plasminogen activator inhibitor (PAI-1) [88, 89]. Secondly, increased D-dimer levels in untreated OSAS have been correlated with severity of nocturnal hypoxemia, characteristic of OSAS [90]. Von Känel et al., found that OSAS patients showed lower mesor (mean) and amplitude (difference between maximum and minimum activity) of D-dimer. However, there were no significant differences in changes of periodic pattern and in day/ night rhythm parameters of prothrombotic markers pre- to posttreatment between the CPAP and placebo condition [91].

Thirdly, sleep fragmentation and sleep efficiency data have been associated with increased levels of von Willebrand factor and soluble tissue factor, two markers of a prothrombotic state [92].

3.6. Endothelial Dysfunction. Endothelial dysfunction is an early marker of vascular abnormality preceding clinically overt cardiovascular disease [93-95]. It is known from years ago that endothelial dysfunction identified in the peripheral vasculature strongly predicts coronary disease [96].

The intact endothelium regulates vascular tone and repair capacity, maintaining proinflammatory, anti-inflammatory, and coagulation homeostasis. Alteration of these homeostatic pathways results in endothelial dysfunction before structural changes in the vasculature. The hypoxia, hypercapnia, and pressor surges accompanying obstructive apneic events may serve as potent stimuli for the release of vasoactive substances. Levels of nitric oxide, a major vasodilator substance released by the endothelium, have been found to be decreased in OSAS patients, and these levels normalize with CPAP therapy [97].

In OSAS, endothelial dysfunction could be caused by both hypoxia-reoxygenation cycles and chronic sleep fragmentation produced by repetitive arousals. A causal relationship between OSAS and endothelial dysfunction was demonstrated by a study in which flow-mediated dilation in the forearm was improved by CPAP treatment $[98,99]$. Levels of nitric oxide, a major vasodilator substance released by the endothelium, have been found to be decreased in OSAS patients, and these levels normalize with CPAP therapy [100].

A number of studies involving OSAS patients indicate an associated endothelial dysfunction [101-103] that improves after CPAP [104, 105]. In addition to the fact that OSAS comorbidities (e.g., hypertension, diabetes, hyperlipidaemia, and smoking) may result in endothelial dysfunction, OSAS itself may be an independent risk factor.

Among the most important vasoconstrictive substances is endothelin-1, a peptide hormone secreted under the influence of hypoxia [106]. Several studies have reported higher endothelin-1 levels in OSAS patients [107, 108]; however, Grimpen et al. report conflicting findings [109]. This divergence might be explained by differences in study design. The groups studied by Phillips and Saarelainen had more severe disease and, thus, underwent more severe oxygen desaturations that acted as a trigger for endothelin-1 secretion. Gjørup et al. showed that hypertensive OSAS patients had greater nocturnal and diurnal endothelin-1 plasma levels than healthy controls, suggesting that OSAS does not affect plasma endothelin-1 levels in the absence of coexistent cardiovascular diseases [110].

The inconsistency of the above endothelin-1 levels likely reflects the predominantly abluminal release of endothelin. Using rat models of arterial hypertension, several authors have reported elevated vascular production of endothelin-1, while circulating levels remained similar to controls [111, 112]. This demonstrates that circulating levels of endothelin-1 do not exclude elevated vascular production in OSAS.

In recent years, endothelial progenitor cells have gained a central role in vascular regeneration and endothelial repair capacity through angiogenesis and restoring endothelial function of injured blood vessels. Endothelial dysfunction is frequently present in OSAS [113] and may have a potential role in the pathogenesis of vascular diseases that is pertinent to OSAS [114].

Furthermore, It has been reported that microvascular endothelial function is affected by OSAS predominantly through increased oxidative stress, and treatment of OSAS may improve endothelial function mainly by reducing oxidative stress $[115,116]$.

3.7. Vibration Resulting from Snoring. Snoring associated vibration energy transmission from the upper airway to the carotid artery has been hypothesized as a potential atherosclerotic plaque initiating and rupturing event that may provide a pathogenic mechanism linking snoring and embolic stroke. The vibration produced by snoring could lead to vessel wall damage in the carotid arteries $[117,118]$.

In animals models, Howitt et al. demonstrated the transmission of oscillatory pressure waves from the upper airway lumen to the peripharyngeal tissues and across the carotid artery wall to the lumen [119]. Cho et al. found carotid arteries subjected to continuous pericarotid tissue vibration displayed endothelial dysfunction, suggesting a direct plausible mechanism linking heavy snoring to the development of carotid atherosclerosis [120]. Although intriguing, this concept requires further study.

\section{Obesity}

OSAS often coexists with obesity and many epidemiological studies have demonstrated the existence of an association. Significant OSAS is present in approximately $40 \%$ of obese individuals, and about $70 \%$ of OSAS patients are obese [121]. Young et al. estimated that the majority of severe OSAS cases (58\%) were due to obesity [122]. In fact, obesity parameters such as BMI, neck circumference, and visceral fat accumulation have been identified as the most important predictors of OSAS [123, 124].

Obesity is one of the major cardiovascular risk factors associated with OSAS. The OSAS-obesity association may have an influence on other disorders, such as cardiovascular 
diseases. Vgontzas et al. found a strong independent association between OSAS, visceral obesity, and insulin resistance. This author demonstrated that male obese patients with OSAS had a greater amount of computerised tomographydetermined visceral adipose tissue in the abdomen than a group of BMI-matched men without OSAS [125]. Moreover, increased abdominal fat accumulation has been singled out as an independent risk factor for cardiovascular diseases [126]. It has been suggested that upper abdominal obesity is more insulin resistant and releases metabolically active products into the portal circulation.

The mechanism by which obesity can favor the onset of OSAS is not well known, but it could be that central obesity precipitates or exacerbates OSAS because fat deposits in the upper airway affect distensibility [127]. The increased volume of abdominal fat could predispose to hypoventilation during sleep and/or reduce the oxygen reserve, favoring oxygen desaturation during sleep [128]. In recent years, much attention has been focused on the interaction between OSAS and products released by adipose tissue such as leptin, adiponectin, resistin, and ghrelin [129].

4.1. Leptin. Leptin is an adipocyte-derived hormone that regulates body weight through control of appetite and energy expenditure [130]. Furthermore, leptin is a cytokine and is therefore also involved in the inflammatory process. Several studies have shown increased levels of leptin in OSAS suggesting its role in the disease [131-133]. The mechanisms underlying the relation between leptin and OSAS are very diverse and may involve overnight changes in apnea levels $[134,135]$, sleep hypoxemia [136], and hypercapnia [137].

A direct relationship between OSAS and leptin is supported by the fact that effective OSAS treatment with CPAP also influences leptin levels [138, 139]. Although the precise mechanism explaining the effect of CPAP has not yet been elucidated, it can be inferred that reduction in sympathetic activity [140] and improvement in insulin sensitivity play a role [141].

Leptin levels have been proposed as a prognostic marker for OSAS $[142,143]$ and have been implicated in the pathogenesis of OSAS and related cardiovascular disease [132, $144,145]$. Leptin's role had been recently extended into that of participant to oxidative stress, although its exact role in this process is yet to be defined. Elevated leptin levels correlate significantly with several indices of OSAS disease severity such as nocturnal hypoxemia. Leptin may be a counteractive mechanism against chronic intermittent hypoxia-related oxidative stress and may also be a marker for atherosclerosis risk [146].

4.2. Adiponectin. Adiponectin is an adipocyte-derived cytokine with regulatory functions in glucose and lipid metabolism. It also has profound anti-inflammatory and antiatherogenic effects. Levels of plasma adiponectin are decreased in obesity and metabolic syndrome [147, 148]. OSAS has independently been associated with reduced levels of adiponectin $[149,150]$ which may favour cardiovascular disease development. The recurrent hypoxia-reoxygenation attacks in OSAS patients may activate oxidative stress and lead to low levels of adiponectin [151].

Some authors have observed that serum adiponectin levels may be independent of the degree of OSAS [132]. Decreased adiponectin may result from increased sympathetic activity [152] and higher levels of cytokines such as IL6 and $\mathrm{TNF} \alpha$ [153]. In fact, there are conflicting reports as to whether CPAP treatment of OSAS effectively normalizes adiponectin levels [154, 155].

Obesity has been implicated in the relation between OSAS and adiponectin [156]. In a study involving media under hypoxic conditions in an ex vivo mouse model, adiponectin secretion was measured. In obese mice, hypoxic stress reduced adiponectin in the supernatant of mesenteric fat tissue but not subcutaneous fat tissue. These findings suggest that abdominal obesity, representing abundant mesenteric fat tissue susceptible to hypoxic stress, partly explains adiponectin levels in OSAS patients, and that reduction of visceral fat accumulation may combat OSAS-related atherosclerotic cardiovascular diseases in abdominal obesity [157].

4.3. Resistin. Resistin is a white adipose tissue hormone whose function has yet to be established. Evidence suggests that resistin is involved in pathological processes leading to cardiovascular disease including inflammation, endothelial dysfunction, thrombosis, angiogenesis, and smooth muscle cell dysfunction [158]. In a study of 20 obese OSAS patients, Harsch et al. found that CPAP treatment of OSAS had no significant influence on resistin levels [159]. In OSAS patients, hypoxic stress during sleep may enhance resistin production, possibly mediating systemic inflammatory processes. Through its effect on OSAS, CPAP therapy may help control resistin production [160].

4.4. Ghrelin. Ghrelin is a hormone that influences appetite and fat accumulation and its physiological effects are opposite to those of leptin. Current experimental evidence suggests that ghrelin may act centrally to decrease sympathetic nervous system activity through peripheral afferent nerve [161]. Thus, administration of ghrelin might become a unique new therapy for cardiovascular diseases [162].

In a study of 30 obese OSAS patients, Harsch et al. found that plasma ghrelin levels were significantly higher in OSAS patients than in controls. These elevated ghrelin levels could not be explained by obesity alone, since they rapidly decreased with CPAP therapy [163]. In a study of 55 consecutive OSAS patients, the study group presented significantly higher serum ghrelin levels than controls. No significant difference was noted in the levels of leptin, adiponectin, and resistin. There was a significant positive correlation between ghrelin and AHI [164].

Increased ghrelin levels have been found to support the presence of increased appetite and caloric intake in obese patients with OSAS, which in turn may further promote the severity of the underlying conditions [165]. In obese children, OSAS is associated with daytime sleepiness, elevation of proinflammatory cytokines, increased leptin, and decreased adiponectin [166]. However, in a recent study, OSAS patients 
with excessive daytime sleepiness were associated with increased circulating hypocretin-1 and decreased circulating ghrelin levels. This relationship is independent of AHI and obesity [167].

\section{OSAS and Insulin Resistance}

Dysglycemia and diabetes also increase the risk of developing cardiovascular disease [168]. With respect to OSAS, Mondini and Guilleminault found increased frequency of abnormal breathing during sleep in both lean and obese diabetics [169]. Elmasry et al. studied 116 hypertensive men and found a 36\% prevalence of severe OSAS in diabetes patients compared to $15 \%$ in controls [170]. West et al. involving men with type 2 diabetes also reported a very high prevalence of OSAS (23\%) [171, 172]. Several studies have reported that diabetic subjects with autonomic neuropathy, regardless of severity, had a relatively high prevalence of OSAS (26\% and 30\%). $[153,173]$.

OSAS might be a manifestation of an endocrine/ metabolic abnormality with a strong role played by insulin resistance [174-176]. A variety of studies based on animal models have shown that hypoxia can alter glucose homeostasis $[177,178]$. Polotsky et al. described that long-term exposure to intermittent hypoxia increased levels of insulin and glucose intolerance in obese, leptin-deficient mice [179]. Humans exposed to hypoxia present worsened glucose tolerance [180].

Most studies involving OSAS and insulin resistance have demonstrated an association between these two diseases, regardless of obesity $[181,182]$. In a large population-based study involving normoglycemic hypertensive men, Resnick et al. found that the severity of OSAS was associated with increased insulin resistance [183]. Insulin resistance is associated with states of inflammation. Monocyte chemoattractant protein-1 levels are elevated in OSAS and may be involved in the pathogenesis of insulin resistance in these patients $[184,185]$.

\section{Metabolic Syndrome and OSAS}

Metabolic syndrome is an emerging public health problem that represents a constellation of cardiovascular risk factors [186]. The association of metabolic syndrome with cardiovascular disease was already observed more than 40 years ago [187]. In addition, Reaven confirmed that metabolic syndrome was a well-established risk factor for cardiovascular disease [188].

The diagnosis of metabolic syndrome is based on a variety of criteria. According to the National Cholesterol Education Program (NCEP) guidelines, a diagnosis of metabolic syndrome requires three or more of the following risk factors: waist circumference $102 \mathrm{~cm}$, triglycerides $1.7 \mathrm{mmol} / \mathrm{L}$, HDL cholesterol < $1.04 \mathrm{mmol} / \mathrm{L}$, blood pressure $130 / 85 \mathrm{mmHg}$, and fasting glucose $6.1 \mathrm{mmol} / \mathrm{L}$ [189].

The prevalence of metabolic syndrome is markedly higher among OSAS patients. Ambrosetti et al. studied 89 consecutive OSAS patients and found metabolic syndrome in 53\% of them [190]. Obese OSAS patients may have an increased rate of metabolic syndrome and higher levels of serum lipids, fasting glucose, leptin, and fibrinogen than obese subjects without OSAS. Thus, clinicians should be encouraged to systematically evaluate the presence of metabolic abnormalities in OSAS and vice versa [191] (Figure 2).

A number of previous epidemiological studies have found links between OSAS and metabolic syndrome. Vgontzas et al. reported that fasting glucose and insulin levels were significantly higher in OSAS patients compared to weightmatched control subjects. They also found that OSAS led to systemic inflammation and metabolic syndrome [192]. Gruber et al. prospectively studied 38 subjects with OSAS and 41 controls. After adjusting for age, BMI, and smoking, OSAS patients were found to be nearly six times more likely to have metabolic syndrome than control group [193]. In a 255subject study by Lam et al. a similar likelihood was reported [194]. Shina et al. reported that C-reactive protein was higher in patients with both OSAS and metabolic syndrome [195]. Bonsignore et al. conclude that the metabolic syndrome occurs in about half of OSAS patients, irrespective of daytime sleepiness, and is a reliable marker of insulin resistance [196].

Both OSAS and metabolic syndrome may exert negative synergistic effects on the cardiovascular system through multiple mechanisms $[197,198]$. In a study by Su et al., metabolic factors such as a higher BMI and fasting blood glucose and a lower HDL-cholesterol level were more strongly associated with elevated cardiovascular disease than with OSAS severity, suggesting that metabolic parameters are important contributors to cardiovascular diseases and should be corrected in patients with OSAS [199]. In a double-blind, placebo-controlled trial in OSAS patients, 3 months of CPAP therapy lowers blood pressure and partially reverses metabolic abnormalities [200].

\section{OSAS and COPD}

COPD is a systemic disease with multiple effects on endorgans including organs in the cardiovascular system [201]. Patients with diagnosed and treated COPD are at increased risk for hospitalizations and deaths due to cardiovascular diseases $[202,203]$. Several studies have focused on the relation between endothelial dysfunction and COPD [204206].

Systemic inflammation is the main atherothrombotic abnormality in COPD, but hypoxia-related platelet activation, procoagulant status, and oxidative stress may play a role $[207,208]$. Mills et al. showed that patients with COPD have increased arterial stiffness and blood pressure in comparison with controls matched for age and smoking status [209]. Furthermore, there is evidence that COPD patients have a perturbed neurohumoral regulatory system leading to sympathovagal imbalance $[210,211]$. This process may be related to chronic respiratory or metabolic conditions that manifest hypoxia, hypercapnia, and acidosis and elicit a maladaptive autonomic and inflammatory response [212].

OSAS may coexist with COPD and this combination has been the focus of extensive study. Flenley referred to it as "overlap syndrome" [213]. Overlap patients present more nocturnal desaturation than patients with either OSAS or 


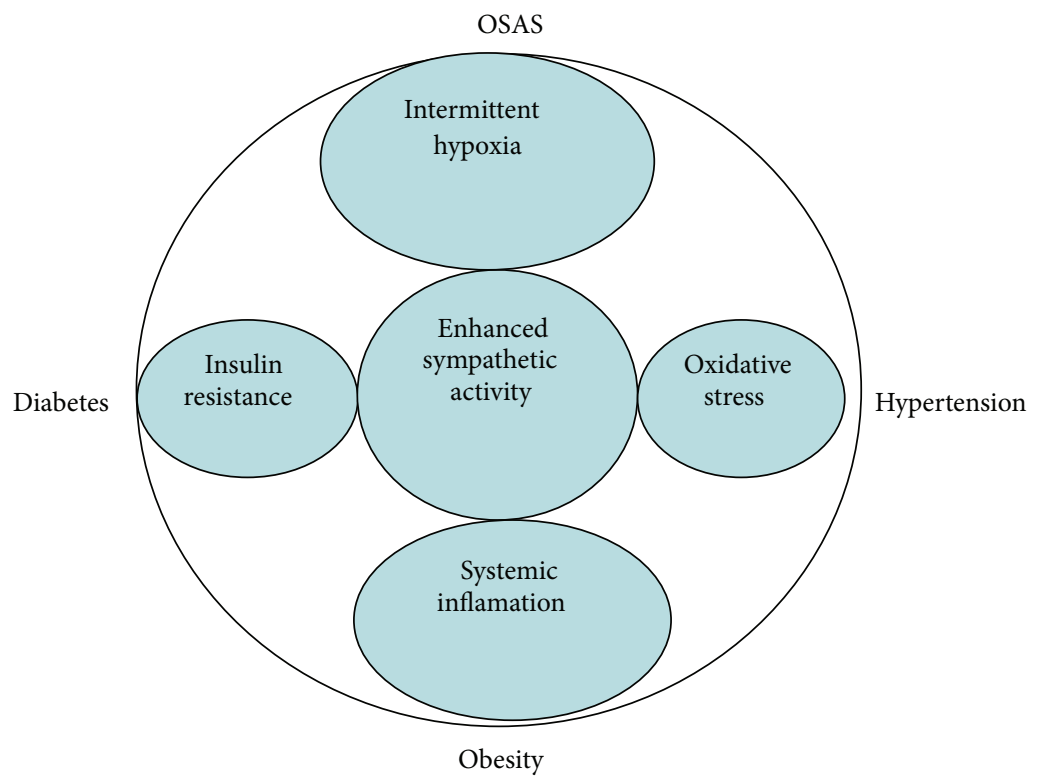

FIGURE 2: Obstructive sleep apnea syndrome and metabolic syndrome. Current perspective.

COPD alone [214]. Individuals with overlap syndrome are at greater risk for pulmonary hypertension, right heart failure, and hypercapnia than patients who have either COPD or OSAS alone [215].

As inflammatory diseases, both OSAS and COPD are associated with higher cardiovascular risk. The mechanisms that may be involved include vascular inflammation, endothelial dysfunction, and tonic elevation of sympathetic neural activity. In sum, OSAS is one of the most frequent COPD comorbidities and may bring on increased inflammation [216-218]. The overlap syndrome is associated with an increased risk of death and hospitalization because of COPD exacerbation. CPAP treatment was associated with improved survival and decreased hospitalizations in patients with overlap syndrome [219]. Treatment consists of CPAP or noninvasive positive pressure ventilation, with or without associated $\mathrm{O} 2$, for correction of the upper airway obstructive episodes and hypoxemia during sleep [220, 221].

\section{Conclusions}

OSAS and intermittent hypoxia are associated with early vascular changes. Animal and clinical data support a specific role for intermittent hypoxia in promoting cellular changes at the vascular wall level thus triggering atherosclerosis. Independently, OSAS impairs endothelial function by altering regulation of endothelial vasomotor tone and repair capacity while promoting vascular inflammation and oxidative stress.

There is increasing evidence of a causal relationship between OSAS and metabolic dysfunction. OSAS, by intermittent hypoxia, may induce or exacerbate various aspects of metabolic syndrome. Clinical studies show that OSAS can affect glucose metabolism, cholesterol, and inflammatory markers. Identification of OSAS as a potential causative factor in metabolic syndrome would have significant clinical impact and could improve the management and understanding of both disorders.

The association of OSAS with endocrine-metabolic and cardiovascular alterations indicates that, more than a local abnormality, OSAS should be considered a systemic disease. A vicious cycle may also appear involving hypoxemiareoxygenation cycles, oxidative stress, and elaboration of proinflammatory cytokines promoting a more generalized inflammatory state.

Sleep apnea research is an intriguing field providing considerable contributions to the cardiovascular literature with exciting insights for clinicians, basic scientists, and epidemiologists.

\section{Abbreviations}

OSAS: Obstructive sleep apnea syndrome

CPAP: Continuous positive airway pressure

COPD: Chronic obstructive pulmonary disease

AHI: Apnea hypopnea index

BMI: $\quad$ Body mass index

PAI: Plasminogen activator inhibitor

ATP: Adenosine triphosphate

eNOS: Endothelial nitric oxide synthase

NFא $\beta$ : Nuclear factor-kappaB

NADPH: Nicotinamide adenine dinucleotide phosphate

IL-8: $\quad$ Interleukin 8

IL-6: Interleukin 6

ICAM: Intercellular adhesion molecule-1

RANTES: Regulated and normal T cell expressed and secreted

CCL5: Chemokine (C-C motif) ligand 5

TNF $\alpha$ : Tumor necrosis factor alpha

HDL: High-density lipoprotein. 


\section{References}

[1] T. Young, M. Palta, J. Dempsey, J. Skatrud, S. Weber, and S. Badr, "The occurrence of sleep-disordered breathing among middleaged adults," The New England Journal of Medicine, vol. 328, no. 17, pp. 1230-1235, 1993.

[2] J. E. Remmers, W. J. DeGroot, E. K. Sauerland, and A. M. Anch, "Pathogenesis of upper airway occlusion during sleep," Journal of Applied Physiology Respiratory Environmental and Exercise Physiology, vol. 44, no. 6, pp. 931-938, 1978.

[3] M. Anstead and B. Phillips, "The spectrum of sleep-disordered breathing," Respiratory Care Clinics of North America, vol. 5, no. 3, pp. 363-377, 1999.

[4] E. Lugaresi and G. Plazzi, "Heavy snorer disease: from snoring to the sleep apnea syndrome-an overview," Respiration, vol. 64, no. 1, pp. 11-21, 1997.

[5] C. Guilleminault, R. Stoohs, T. Shiomi, C. Kushida, and I. Schnittger, "Upper airway resistance syndrome, nocturnal blood pressure monitoring, and borderline hypertension," Chest, vol. 109, no. 4, pp. 901-908, 1996.

[6] K. I. Berger, I. Ayappa, B. Chatr-Amontri et al., "Obesity hypoventilation syndrome as a spectrum of respiratory disturbances during sleep," Chest, vol. 120, no. 4, pp. 1231-1238, 2001.

[7] H. Gastaut, C. A. Tassinari, and B. Duron, "Polygraphic study of diurnal and nocturnal (hypnic and respiratory) episodal manifestations of Pickwick syndrome," Revue Neurologique, vol. 112, no. 6, pp. 568-579, 1965.

[8] J. M. Marin, S. J. Carrizo, E. Vicente, and A. G. N. Agusti, "Longterm cardiovascular outcomes in men with obstructive sleep apnoea-hypopnoea with or without treatment with continuous positive airway pressure: an observational study," The Lancet, vol. 365, no. 9464, pp. 1046-1053, 2005.

[9] J. Terán-Santos, A. Jiménez-Gómez, and J. Cordero-Guevara, "The association between sleep apnea and the risk of traffic accidents," The New England Journal of Medicine, vol. 340, no. 11, pp. 847-851, 1999.

[10] A. Chaouat, E. Weitzenblum, J. Krieger, T. Ifoundza, M. Oswald, and R. Kessler, "Association of chronic obstructive pulmonary disease and sleep apnea syndrome," The American Journal of Respiratory and Critical Care Medicine, vol. 151, no. 1, pp. 82-86, 1995.

[11] O. Oldenburg, B. Lamp, L. Faber, H. Teschler, D. Horstkotte, and V. Töpfer, "Sleep-disordered breathing in patients with symptomatic heart failure. A contemporary study of prevalence in and characteristics of 700 patients," European Journal of Heart Failure, vol. 9, no. 3, pp. 251-257, 2007.

[12] F. Pichel, C. Zamarrón, F. Magán, F. del Campo, R. AlvarezSala, and J. R. Rodríguez Suarez, "Health-related quality of life in patients with obstructive sleep apnea: effects of long-term positive airway pressure treatment," Respiratory Medicine, vol. 98, no. 10, pp. 968-976, 2004.

[13] S. R. Coughlin, L. Mawdsley, J. A. Mugarza, P. M. A. Calverley, and J. P. H. Wilding, "Obstructive sleep apnoea is independently associated with an increased prevalence of metabolic syndrome," European Heart Journal, vol. 25, no. 9, pp. 735-741, 2004.

[14] J. Durán, S. Esnaola, R. Rubio, and Á. Iztueta, “Obstructive sleep apnea-hypopnea and related clinical features in a populationbased sample of subjects aged 30 to $70 \mathrm{yr}$," The American Journal of Respiratory and Critical Care Medicine, vol. 163, no. 3, part 1, pp. 685-689, 2001.
[15] Z. F. Udwadia, A. V. Doshi, S. G. Lonkar, and C. I. Singh, "Prevalence of sleep-disordered breathing and sleep apnea in middle-aged urban Indian men," The American Journal of Respiratory and Critical Care Medicine, vol. 169, no. 2, pp. 168173, 2004.

[16] S. K. Sharma, S. Kumpawat, A. Banga, and A. Goel, "Prevalence and risk factors of obstructive sleep apnea syndrome in a population of Delhi, India," Chest, vol. 130, no. 1, pp. 149-156, 2006.

[17] R. Pływaczewski, M. Bednarek, L. Jonczak, and J. Zieliński, "Sleep-disordered breathing in a middle-aged and older Polish urban population," Journal of Sleep Research, vol. 17, no. 1, pp. 73-81, 2008.

[18] S. Ancoli-Israel and T. Coy, "Are breathing disturbances in elderly equivalent to sleep apnea syndrome?" Sleep, vol. 17, no. 1, pp. 77-83, 1994.

[19] T. Young, "Sleep-disordered breathing in older adults: is it a condition distinct from that in middle-aged adults?" Sleep, vol. 19, no. 7, pp. 529-530, 1996.

[20] M. M. Fung, K. Peters, S. Redline et al., "Decreased slow wave sleep increases risk of developing hypertension in elderly men," Hypertension, vol. 58, no. 4, pp. 596-603, 2011.

[21] T. T. Bekci, M. Kayrak, A. Kiyici et al., "The association among lipoprotein-associated phospholipase A2 levels, total antioxidant capacity and arousal in male patients with OSA," International Journal of Medical Sciences, vol. 8, no. 5, pp. 369376, 2011.

[22] M. Follenius, J. Krieger, M. O. Krauth, F. Sforza, and G. Brandenberger, "Obstructive sleep apnea treatment: peripheral and central effects on plasma renin activity and aldosterone," Sleep, vol. 14, no. 3, pp. 211-217, 1991.

[23] D. S. Møller, P. Lind, B. Strunge, and E. B. Pedersen, "Abnormal vasoactive hormones and 24-hour blood pressure in obstructive sleep apnea," The American Journal of Hypertension, vol. 16, no. 4, pp. 274-280, 2003.

[24] S. R. Patel, X. Zhu, A. Storfer-Isser et al., "Sleep duration and biomarkers of inflammation," Sleep, vol. 32, no. 2, pp. 200-204, 2009.

[25] D. Gozal, L. D. Serpero, L. Kheirandish-Gozal, O. S. Capdevila, A. Khalyfa, and R. Tauman, "Sleep measures and morning plasma TNF- $\alpha$ levels in children with sleep-disordered breathing," Sleep, vol. 33, no. 3, pp. 319-325, 2010.

[26] V. K. Somers, A. L. Mark, and F. M. Abboud, "Sympathetic activation by hypoxia and hypercapnia-implications for sleep apnea," Clinical and Experimental Hypertension A, vol. 10, no. 1, pp. 413-422, 1988.

[27] V. A. Imadojemu, Z. Mawji, A. Kunselman, K. S. Gray, C. S. Hogeman, and U. A. Leuenberger, "Sympathetic chemoreflex responses in obstructive sleep apnea and effects of continuous positive airway pressure therapy," Chest, vol. 131, no. 5, pp. 14061413, 2007.

[28] N. R. Prabhakar, R. D. Fields, T. Baker, and E. C. Fletcher, "Intermittent hypoxia: cell to system," The American Journal of Physiology, vol. 281, no. 3, pp. L524-L528, 2001.

[29] V. K. Somers, M. E. Dyken, M. P. Clary, and F. M. Abboud, "Sympathetic neural mechanisms in obstructive sleep apnea," Journal of Clinical Investigation, vol. 96, no. 4, pp. 1897-1904, 1995.

[30] R. Tamisier, J. L. Pépin, J. Rémy et al., "14 nights of intermittent hypoxia elevate daytime blood pressure and sympathetic activity in healthy humans," European Respiratory Journal, vol. 37, no. 1, pp. 119-128, 2011. 
[31] R. Von Känel and J. E. Dimsdale, "Hemostatic alterations in patients with obstructive sleep apnea and the implications for cardiovascular disease," Chest, vol. 124, no. 5, pp. 1956-1967, 2003.

[32] R. E. Maser, M. J. Lenhard, A. A. Rizzo, and A. A. Vasile, "Continuous positive airway pressure therapy improves cardiovascular autonomic function for persons with sleep-disordered breathing," Chest, vol. 133, no. 1, pp. 86-91, 2008.

[33] O. Marrone, A. Salvaggio, A. L. Bue et al., "Blood pressure changes after automatic and fixed CPAP in obstructive sleep apnea: relationship with nocturnal sympathetic activity," Clinical and Experimental Hypertension, vol. 33, no. 6, pp. 373-380, 2011.

[34] G. V. Robinson, J. C. T. Pepperell, H. C. Segal, R. J. O. Davies, and J. R. Stradling, "Circulating cardiovascular risk factors in obstructive sleep apnoea: data from randomised controlled trials," Thorax, vol. 59, no. 9, pp. 777-782, 2004.

[35] R. Schulz, S. Mahmoudi, K. Hattar et al., "Enhanced release of superoxide from polymorphonuclear neutrophils in obstructive sleep apnea: impact of continuous positive airway pressure therapy," The American Journal of Respiratory and Critical Care Medicine, vol. 162, no. 2, part 1, pp. 566-570, 2000.

[36] L. Lavie, A. Vishnevsky, and P. Lavie, "Evidence for lipid peroxidation in obstructive sleep apnea," Sleep, vol. 27, no. 1, pp. 123-128, 2004.

[37] G. E. Carpagnano, S. A. Kharitonov, O. Resta, M. P. FoschinoBarbaro, E. Gramiccioni, and P. J. Barnes, "8-isoprostane, a marker of oxidative stress, is increased in exhaled breath condensate of patients with obstructive sleep apnea after night and is reduced by continuous positive airway pressure therapy," Chest, vol. 124, no. 4, pp. 1386-1392, 2003.

[38] A. Alonso-Fernández, F. García-Río, M. A. Arias et al., "Effects of CPAP on oxidative stress and nitrate efficiency in sleep apnoea: a randomised trial," Thorax, vol. 64, no. 7, pp. 581-586, 2009.

[39] P. Celec, J. Hodosy, M. Behuliak et al., "Oxidative and carbonyl stress in patients with obstructive sleep apnea treated with continuous positive airway pressure," Sleep and Breathing, vol. 16, no. 2, pp. 393-398, 2012.

[40] G. Malakasioti, E. Alexopoulos, C. Befani et al., "Oxidative stress and inflammatory markers in the exhaled breath condensate of children with OSA," Sleep and Breathing, vol. 16, no. 3, pp. 703-708, 2012.

[41] S. Teramoto, H. Kume, H. Yamamoto et al., "Effects of oxygen administration on the circulating vascular endothelial growth factor (VEGF) levels in patients with obstructive sleep apnea syndrome," Internal Medicine, vol. 42, no. 8, pp. 681-685, 2003.

[42] O. Marrone, A. Salvaggio, M. Gioia et al., "Reticulocytes in untreated obstructive sleep apnoea," Monaldi Archives for Chest Disease, vol. 69, no. 3, pp. 107-113, 2008.

[43] E. Belaidi, M. Joyeux-Faure, C. Ribuot, S. H. Launois, P. Levy, and D. Godin-Ribuot, "Major role for hypoxia inducible factor1 and the endothelin system in promoting myocardial infarction and hypertension in an animal model of obstructive sleep apnea," Journal of the American College of Cardiology, vol. 53, no. 15, pp. 1309-1317, 2009.

[44] L. Dyugovskaya, P. Lavie, and L. Lavie, "Increased adhesion molecules expression and production of reactive oxygen species in leukocytes of sleep apnea patients," The American Journal of Respiratory and Critical Care Medicine, vol. 165, no. 7, pp. 934939, 2002.
[45] A. Park, H. Nagase, S. V. Kumar, and Y. J. Suzuki, "Effects of intermittent hypoxia on the heart," Antioxidants and Redox Signaling, vol. 9, no. 6, pp. 723-729, 2007.

[46] A. Barceló, F. Barbé, M. de la Peña et al., "Antioxidant status in patients with sleep apnoea and impact of continuous positive airway pressure treatment," European Respiratory Journal, vol. 27, no. 4, pp. 756-760, 2006.

[47] M. Grebe, H. J. Eisele, N. Weissmann et al., "Antioxidant vitamin C improves endothelial function in obstructive sleep apnea," The American Journal of Respiratory and Critical Care Medicine, vol. 173, no. 8, pp. 897-901, 2006.

[48] J. L. Lattimore, I. Wilcox, S. Nakhla, M. Langenfeld, W. Jessup, and D. S. Celermajer, "Repetitive hypoxia increases lipid loading in human macrophages-a potentially atherogenic effect," Atherosclerosis, vol. 179, no. 2, pp. 255-259, 2005.

[49] E. Wysocka, S. Cofta, M. Cymerys, J. Gozdzik, L. Torlinski, and H. Batura-Gabryel, "The impact of the sleep apnea syndrome on oxidant-antioxidant balance in the blood of overweight and obese patients," Journal of Physiology and Pharmacology, vol. 59, supplement 6, pp. 761-769, 2008.

[50] S. Jelic, D. J. Lederer, T. Adams et al., "Vascular inflammation in obesity and sleep apnea," Circulation, vol. 121, no. 8, pp. 10141021, 2010.

[51] M. A. Alzoghaibi and A. S. BaHammam, "The effect of one night of continuous positive airway pressure therapy on oxidative stress and antioxidant defense in hypertensive patients with severe obstructive sleep apnea," Sleep and Breathing, vol. 16, no. 2, pp. 499-504, 2012.

[52] D. Nair, E. A. Dayyat, S. X. Zhang, Y. Wang, and D. Gozal, "Intermittent hypoxia-induced cognitive deficits are mediated by NADPH oxidase activity in a murine model of sleep apnea," PLoS ONE, vol. 6, no. 5, Article ID e19847, 2011.

[53] G. Devouassoux, P. Lévy, E. Rossini et al., "Sleep apnea is associated with bronchial inflammation and continuous positive airway pressure-induced airway hyperresponsiveness," Journal of Allergy and Clinical Immunology, vol. 119, no. 3, pp. 597-603, 2007.

[54] G. E. Carpagnano, A. Spanevello, R. Sabato et al., "Systemic and airway inflammation in sleep apnea and obesity: the role of ICAM-1 and IL-8," Translational Research, vol. 155, no. 1, pp. 35-43, 2010.

[55] S. Cofta, E. Wysocka, S. Dziegielewska-Gesiak et al., "Plasma selectins in patients with obstructive sleep apnea," Advances in Experimental Medicine and Biology, vol. 756, pp. 113-119, 2013.

[56] A. A. El-Solh, M. J. Mador, P. Sikka, R. S. Dhillon, D. Amsterdam, and B. J. B. Grant, "Adhesion molecules in patients with coronary artery disease and moderate-to-severe obstructive sleep apnea," Chest, vol. 121, no. 5, pp. 1541-1547, 2002.

[57] C. Zamarrón-Sanz, J. Ricoy-Galbaldon, F. Gude-Sampedro, and A. Riveiro-Riveiro, "Plasma levels of vascular endothelial markers in obstructive sleep apnea," Archives of Medical Research, vol. 37, no. 4, pp. 552-555, 2006.

[58] L. Dyugovskaya, A. Polyakov, P. Lavie, and L. Lavie, "Delayed neutrophil apoptosis in patients with sleep apnea," The American Journal of Respiratory and Critical Care Medicine, vol. 177, no. 5, pp. 544-554, 2008.

[59] S. Imagawa, Y. Yamaguchi, K. Ogawa et al., "Interleukin-6 and tumor necrosis factor- $\alpha$ in patients with obstructive sleep apnea-hypopnea syndrome," Respiration, vol. 71, no. 1, pp. 2429, 2004.

[60] M. de la Peña Bravo, L. D. Serpero, A. Barceló, F. Barbé, A. Agustí, and D. Gozal, "Inflammatory proteins in patients with 
obstructive sleep apnea with and without daytime sleepiness," Sleep and Breathing, vol. 11, no. 3, pp. 177-185, 2007.

[61] P. Steiropoulos, I. Kotsianidis, E. Nena et al., "Long-term effect of continuous positive airway pressure therapy on infammation markers of patients with obstructive sleep apnea syndrome," Sleep, vol. 32, no. 4, pp. 537-543, 2009.

[62] M. A. Arias, F. García-Río, A. Alonso-Fernández et al., "CPAP decreases plasma levels of soluble tumour necrosis factor- $\alpha$ receptor 1 in obstructive sleep apnoea," European Respiratory Journal, vol. 32, no. 4, pp. 1009-1015, 2008.

[63] R. Ross, "Atherosclerosis-an inflammatory disease," The New England Journal of Medicine, vol. 340, no. 2, pp. 115-126, 1999.

[64] G. K. Hansson, "Mechanisms of disease: inflammation, atherosclerosis, and coronary artery disease," The New England Journal of Medicine, vol. 352, no. 16, pp. 1685-1695, 2005.

[65] J. R. Delanghe, M. R. Langlois, D. de Bacquer et al., "Discriminative value of serum amyloid $\mathrm{A}$ and other acute-phase proteins for coronary heart disease," Atherosclerosis, vol. 160, no. 2, pp. 471-476, 2002.

[66] A. Svatikova, R. Wolk, A. S. Shamsuzzaman, T. Kara, E. J. Olson, and V. K. Somers, "Serum amyloid a in obstructive sleep apnea," Circulation, vol. 108, no. 12, pp. 1451-1454, 2003.

[67] E. Kuramoto, S. Kinami, Y. Ishida, H. Shiotani, and Y. Nishimura, "Continuous positive nasal airway pressure decreases levels of serum amyloid A and improves autonomic function in obstructive sleep apnea syndrome," International Journal of Cardiology, vol. 135, no. 3, pp. 338-345, 2009.

[68] M. K. Rutter, J. B. Meigs, L. M. Sullivan, R. B. D’Agostino Sr., and P. W. F. Wilson, "C-reactive protein, the metabolic syndrome, and prediction of cardiovascular events in the Framingham offspring study," Circulation, vol. 110, no. 4, pp. 380-385, 2004.

[69] A. S. M. Shamsuzzaman, M. Winnicki, P. Lanfranchi et al., "Elevated C-reactive protein in patients with obstructive sleep apnea," Circulation, vol. 105, no. 21, pp. 2462-2464, 2002.

[70] O. Kokturk, T. U. Ciftci, E. Mollarecep, and B. Ciftci, "Elevated C-reactive protein levels and increased cardiovascular risk in patients with obstructive sleep apnea syndrome," International Heart Journal, vol. 46, no. 5, pp. 801-809, 2005.

[71] S. Taheri, D. Austin, L. Lin, F. J. Nieto, T. Young, and E. Mignot, "Correlates of serum C-reactive protein (CRP) - no association with sleep duration or sleep disordered breathing," Sleep, vol. 30, no. 8, pp. 991-996, 2007.

[72] T. Yokoe, K. Minoguchi, H. Matsuo et al., "Elevated levels of Creactive protein and interleukin- 6 in patients with obstructive sleep apnea syndrome are decreased by nasal continuous positive airway pressure," Circulation, vol. 107, no. 8, pp. 11291134, 2003.

[73] S. E. Schiza, C. Mermigkis, P. Panagiotis et al., "C-reactive protein evolution in obstructive sleep apnoea patients under CPAP therapy," European Journal of Clinical Investigation, vol. 40, no. 11, pp. 968-975, 2010.

[74] S. Ryan, C. T. Taylor, and W. T. McNicholas, "Selective activation of inflammatory pathways by intermittent hypoxia in obstructive sleep apnea syndrome," Circulation, vol. 112, no. 17, pp. 2660-2667, 2005.

[75] H. J. Yu, B. R. Lin, H. S. Lee et al., "Sympathetic vesicovascular reflex induced by acute urinary retention evokes proinflammatory and proapoptotic injury in rat liver," The American Journal of Physiology, vol. 288, no. 5, pp. F1005-F1014, 2005.

[76] T. J. Guzik, N. E. Hoch, K. A. Brown et al., "Role of the T cell in the genesis of angiotensin II-induced hypertension and vascular dysfunction," Journal of Experimental Medicine, vol. 204, no. 10, pp. 2449-2460, 2007.

[77] T. Kasai, K. Inoue, T. Kumagai et al., "Plasma pentraxin3 and arterial stiffness in men with obstructive sleep apnea," The American Journal of Hypertension, vol. 24, no. 4, pp. 401-407, 2011.

[78] C. Arnaud, P. C. Beguin, S. Lantuejoul et al., "The inflammatory preatherosclerotic remodeling induced by intermittent hypoxia is attenuated by RANTES/CCL5 inhibition," The American Journal of Respiratory and Critical Care Medicine, vol. 184, no. 6, pp. 724-731, 2011.

[79] A. Carreras, I. Almendros, J. M. Montserrat, D. Navajas, and R. Farré, "Mesenchymal stem cells reduce inflammation in a rat model of obstructive sleep apnea," Respiratory Physiology and Neurobiology, vol. 172, no. 3, pp. 210-212, 2010.

[80] J. S. Querido, A. W. Sheel, R. Cheema, S. van Eeden, A. T. Mulgrew, and N. T. Ayas, "Effects of 10 days of modest intermittent hypoxia on circulating measures of inflammation in healthy humans," Sleep and Breathing, vol. 16, no. 3, pp. 657662, 2012.

[81] K. Zouaoui Boudjeltia, M. Guillaume, C. Henuzet et al., "Fibrinolysis and cardiovascular risk factors: association with fibrinogen, lipids, and monocyte count," European Journal of Internal Medicine, vol. 17, no. 2, pp. 102-108, 2006.

[82] V. Bratseth, A. A. Pettersen, T. B. Opstad, H. Arnesen, and I. Seljeflot, "Markers of hypercoagulability in CAD patients. Effects of single aspirin and clopidogrel treatment," Thrombosis Journal, vol. 10, article 12, 2012.

[83] N. Peled, M. Kassirer, M. R. Kramer et al., "Increased erythrocyte adhesiveness and aggregation in obstructive sleep apnea syndrome," Thrombosis Research, vol. 121, no. 5, pp. 631-636, 2008.

[84] M. Othman, S. P. Gordon, and S. Iscoe, "Repeated inspiratory occlusions in anesthetized rats acutely increase blood coagulability as assessed by thromboelastography," Respiratory Physiology and Neurobiology, vol. 171, no. 1, pp. 61-66, 2010.

[85] W. H. Reinhart, J. Oswald, R. Walter, and M. Kuhn, "Blood viscosity and platelet function in patients with obstructive sleep apnea syndrome treated with nasal continuous positive airway pressure," Clinical Hemorheology and Microcirculation, vol. 27, no. 3-4, pp. 201-207, 2002.

[86] R. von Känel, J. S. Loredo, F. L. Powell, K. A. Adler, and J. E. Dimsdale, "Short-term isocapnic hypoxia and coagulation activation in patients with sleep apnea," Clinical Hemorheology and Microcirculation, vol. 33, no. 4, pp. 369-377, 2005.

[87] M. E. Akinnusi, L. L. Paasch, K. R. Szarpa, P. K. Wallace, and A. A. El Solh, "Impact of nasal continuous positive airway pressure therapy on markers of platelet activation in patients with obstructive sleep apnea," Respiration, vol. 77, no. 1, pp. 2531, 2009.

[88] R. von Känel, J. S. Loredo, S. Ancoli-Israel, and J. E. Dimsdale, "Association between sleep apnea severity and blood coagulability: treatment effects of nasal continuous positive airway pressure," Sleep and Breathing, vol. 10, no. 3, pp. 139-146, 2006.

[89] C. Zamarrón, J. Ricoy, A. Riveiro, and F. Gude, "Plasminogen activator inhibitor-1 in obstructive sleep apnea patients with and without hypertension," Lung, vol. 186, no. 3, pp. 151-156, 2008.

[90] D. Shitrit, N. Peled, A. B. Shitrit et al., "An association between oxygen desaturation and D-dimer in patients with obstructive sleep apnea syndrome," Thrombosis and Haemostasis, vol. 94, no. 3, pp. 544-547, 2005. 
[91] K. R. von Känel, L. Natarajan, S. Ancoli-Israel et al., "Effect of continuous positive airway pressure on day/night rhythm of prothrombotic markers in obstructive sleep apnea," Sleep Medicine, vol. 14, no. 1, pp. 58-65, 2013.

[92] R. von Känel, J. S. Loredo, S. Ancoli-Israel, P. J. Mills, L. Natarajan, and J. E. Dimsdale, "Association between polysomnographic measures of disrupted sleep and prothrombotic factors," Chest, vol. 131, no. 3, pp. 733-739, 2007.

[93] S. J. Cleland, N. Sattar, J. R. Petrie, N. G. Forouhi, H. L. Elliott, and J. M. C. Connell, "Endothelial dysfunction as a possible link between C-reactive protein levels and cardiovascular disease," Clinical Science, vol. 98, no. 5, pp. 531-535, 2000.

[94] H. A. R. Hadi and J. A. Al Suwaidi, "Endothelial dysfunction in diabetes mellitus," Vascular Health and Risk Management, vol. 3, no. 6, pp. 853-876, 2007.

[95] J. P. J. Halcox, A. E. Donald, E. Ellins et al., "Endothelial function predicts progression of carotid intima-media thickness," Circulation, vol. 119, no. 7, pp. 1005-1012, 2009.

[96] T. J. Anderson, A. Uehata, M. D. Gerhard et al., "Close relation of endothelial function in the human coronary and peripheral circulations," Journal of the American College of Cardiology, vol. 26, no. 5, pp. 1235-1241, 1995.

[97] J. Oyama, H. Yamamoto, T. Maeda, A. Ito, K. Node, and N. Makino, "Continuous positive airway pressure therapy improves vascular dysfunction and decreases oxidative stress in patients with the metabolic syndrome and obstructive sleep apnea syndrome," Clinical Cardiology, vol. 35, no. 4, pp. 231-236, 2012.

[98] M. S. M. Ip, H. Tse, B. Lam, K. W. T. Tsang, and W. Lam, "Endothelial function in obstructive sleep apnea and response to treatment," The American Journal of Respiratory and Critical Care Medicine, vol. 169, no. 3, pp. 348-353, 2004.

[99] W. Trzepizur, F. Gagnadoux, P. Abraham et al., "Microvascular endothelial function in obstructive sleep apnea: impact of continuous positive airway pressure and mandibular advancement," Sleep Medicine, vol. 10, no. 7, pp. 746-752, 2009.

[100] J. S. J. Haight and P. G. Djupesland, "Nitric oxide (NO) and obstructive sleep apnea (OSA)," Sleep and Breathing, vol. 7, no. 2, pp. 53-62, 2003.

[101] F. J. Nieto, D. M. Herrington, S. Redline, E. J. Benjamin, and J. A. Robbins, "Sleep apnea and markers of vascular endothelial function in a large community sample of older adults," The American Journal of Respiratory and Critical Care Medicine, vol. 169, no. 3, pp. 354-360, 2004.

[102] M. Kohler, S. Craig, D. Nicoll, P. Leeson, R. J. O. Davies, and J. R. Stradling, "Endothelial function and arterial stiffness in minimally symptomatic obstructive sleep apnea," The American Journal of Respiratory and Critical Care Medicine, vol. 178, no. 9, pp. 984-988, 2008.

[103] M. de la Peña, A. Barceló, F. Barbe et al., "Endothelial function and circulating endothelial progenitor cells in patients with sleep apnea syndrome," Respiration, vol. 76, no. 1, pp. 28-32, 2008.

[104] M. Kohler, A. Stoewhas, L. Ayers et al., "Effects of continuous positive airway pressure therapy withdrawal in patients with obstructive sleep apnea: a randomized controlled trial," The American Journal of Respiratory and Critical Care Medicine, vol. 184, no. 10, pp. 1192-1199, 2011.

[105] M. M. Ciccone, S. Favale, P. Scicchitano et al., "Reversibility of the endothelial dysfunction after CPAP therapy in OSAS patients," International Journal of Cardiology, vol. 158, no. 3, pp. 383-386, 2012.
[106] N. L. Kanagy, B. R. Walker, and L. D. Nelin, "Role of endothelin in intermittent hypoxia-induced hypertension," Hypertension, vol. 37, no. 2, pp. 511-515, 2001.

[107] B. G. Phillips, K. Narkiewicz, C. A. Pesek, W. G. Haynes, M. E. Dyken, and V. K. Somers, "Effects of obstructive sleep apnea on endothelin-1 and blood pressure," Journal of Hypertension, vol. 17, no. 1, pp. 61-66, 1999.

[108] S. Saarelainen and J. Hasan, "Circulating endothelin-1 and obstructive sleep apnoea," European Respiratory Journal, vol. 16, no. 4, pp. 794-795, 2000.

[109] F. Grimpen, P. Kanne, E. Schulz, G. Hagenah, G. Hasenfuß, and S. Andreas, "Endothelin-1 plasma levels are not elevated in patients with obstructive sleep apnoea," European Respiratory Journal, vol. 15, no. 2, pp. 320-325, 2000.

[110] P. H. Gjørup, L. Sadauskiene, J. Wessels, O. Nyvad, B. Strunge, and E. B. Pedersen, "Abnormally increased endothelin-1 in plasma during the night in obstructive sleep apnea: relation to blood pressure and severity of disease," The American Journal of Hypertension, vol. 20, no. 1, pp. 44-52, 2007.

[111] G. P. Rossi and G. Pitter, "Genetic variation in the endothelin system: do polymorphisms affect the therapeutic strategies?" Annals of the New York Academy of Sciences, vol. 1069, pp. 3450, 2006.

[112] U. Pohl and R. Busse, "Differential vascular sensitivity to luminally and adventitially applied endothelin-1," Journal of Cardiovascular Pharmacology, vol. 13, supplement 5, pp. S188S190, 1989.

[113] L. Kheirandish-Gozal, R. Bhattacharjee, J. Kim, H. B. Clair, and D. Gozal, "Endothelial progenitor cells and vascular dysfunction in children with obstructive sleep apnea," The American Journal of Respiratory and Critical Care Medicine, vol. 182, no. 1, pp. 92-97, 2010.

[114] S. Berger and L. Lavie, "Endothelial progenitor cells in cardiovascular disease and hypoxia-potential implications to obstructive sleep apnea," Translational Research, vol. 158, no. 1, pp. 1-13, 2011.

[115] B. T. Patt, D. Jarjoura, D. N. Haddad et al., "Endothelial dysfunction in the microcirculation of patients with obstructive sleep apnea," The American Journal of Respiratory and Critical Care Medicine, vol. 182, no. 12, pp. 1540-1545, 2010.

[116] N. J. Büchner, I. Quack, M. Woznowski, C. Stähle, U. Wenzel, and L. C. Rump, "Microvascular endothelial dysfunction in obstructive sleep apnea is caused by oxidative stress and improved by continuous positive airway pressure therapy," Respiration, vol. 82, no. 5, pp. 409-417, 2011.

[117] S. A. Lee, T. C. Amis, K. Byth et al., "Heavy snoring as a cause of carotid artery atherosclerosis," Sleep, vol. 31, no. 9, pp. 1207-1213, 2008.

[118] J. Amatoury, L. Howitt, J. R. Wheatley, A. P. Avolio, and T. C. Amis, "Snoring-related energy transmission to the carotid artery in rabbits," Journal of Applied Physiology, vol. 100, no. 5, pp. 1547-1553, 2006.

[119] L. Howitt, K. Kairaitis, J. P. Kirkness et al., "Oscillatory pressure wave transmission from the upper airway to the carotid artery," Journal of Applied Physiology, vol. 103, no. 5, pp. 1622-1627, 2007.

[120] J. Cho, P. K. Witting, M. Verma et al., "Tissue vibration induces carotid artery endothelial dysfunction: a mechanism linking snoring and carotid atherosclerosis?" Sleep, vol. 34, no. 6, pp. 751-757, 2011.

[121] R. Wolk, A. S. M. Shamsuzzaman, and V. K. Somers, "Obesity, sleep apnea, and hypertension," Hypertension, vol. 42, no. 6, pp. 1067-1074, 2003. 
[122] T. Young, P. E. Peppard, and S. Taheri, "Excess weight and sleepdisordered breathing," Journal of Applied Physiology, vol. 99, no. 4, pp. 1592-1599, 2005.

[123] H. Schäfer, D. Pauleit, T. Sudhop, I. Gouni-Berthold, S. Ewig, and H. K. Berthold, "Body fat distribution, serum leptin, and cardiovascular risk factors in men with obstructive sleep apnea," Chest, vol. 122, no. 3, pp. 829-839, 2002.

[124] C. A. Canapari, A. G. Hoppin, T. B. Kinane, B. J. Thomas, M. Torriani, and E. S. Katz, "Relationship between sleep apnea, fat distribution, and insulin resistance in obese children," Journal of Clinical Sleep Medicine, vol. 7, no. 3, pp. 268-273, 2011.

[125] A. N. Vgontzas, D. A. Papanicolaou, E. O. Bixler et al., "Sleep apnea and daytime sleepiness and fatigue: relation to visceral obesity, insulin resistance, and hypercytokinemia," Journal of Clinical Endocrinology and Metabolism, vol. 85, no. 3, pp. 1151$1158,2000$.

[126] H. Nagaretani, T. Nakamura, T. Funahashi et al., "Visceral fat is a major contributor for multiple risk factor clustering in Japanese men with impaired glucose tolerance," Diabetes Care, vol. 24, no. 12, pp. 2127-2133, 2001.

[127] S. Isono, "Obstructive sleep apnea of obese adults: pathophysiology and perioperative airway management," Anesthesiology, vol. 110, no. 4, pp. 908-921, 2009.

[128] A. R. Schwartz, S. P. Patil, A. M. Laffan, V. Polotsky, H. Schneider, and P. L. Smith, "Obesity and obstructive sleep apnea: pathogenic mechanisms and therapeutic approaches," Proceedings of the American Thoracic Society, vol. 5, no. 2, pp. 185-192, 2008.

[129] T. Ronti, G. Lupattelli, and E. Mannarino, "The endocrine function of adipose tissue: an update," Clinical Endocrinology, vol. 64, no. 4, pp. 355-365, 2006.

[130] K. Proulx, D. Richard, and C. Walker, "Leptin regulates appetiterelated neuropeptides in the hypothalamus of developing rats without affecting food intake," Endocrinology, vol. 143, no. 12, pp. 4683-4692, 2002.

[131] B. G. Phillips, M. Kato, K. Narkiewicz, I. Choe, and V. K. Somers, "Increases in leptin levels, sympathetic drive, and weight gain in obstructive sleep apnea," The American Journal of Physiology, vol. 279, no. 1, pp. H234-H237, 2000.

[132] F. Tokuda, Y. Sando, H. Matsui, H. Koike, and T. Yokoyama, "Serum levels of adipocytokines, adiponectin and leptin, in patients with obstructive sleep apnea syndrome," Internal Medicine, vol. 47, no. 21, pp. 1843-1849, 2008.

[133] M. S. M. Ip, K. S. L. Lam, C. Ho, K. W. T. Tsang, and W. Lam, "Serum leptin and vascular risk factors in obstructive sleep apnea," Chest, vol. 118, no. 3, pp. 580-586, 2000.

[134] B. M. Sanner, P. Kollhosser, N. Buechner, W. Zidek, and M. Tepel, "Influence of treatment on leptin levels in patients with obstructive sleep apnoea," European Respiratory Journal, vol. 23, no. 4, pp. 601-604, 2004.

[135] S. R. Patel, L. J. Palmer, E. K. Larkin, N. S. Jenny, D. P. White, and S. Redline, "Relationship between obstructive sleep apnea and diurnal leptin rhythms," Sleep, vol. 27, no. 2, pp. 235-239, 2004.

[136] K. Tatsumi, J. Kasahara, K. Kurosu, N. Tanabe, Y. Takiguchi, and T. Kuriyama, "Sleep oxygen desaturation and circulating leptin in obstructive sleep apnea-hypopnea syndrome," Chest, vol. 127, no. 3, pp. 716-721, 2005.

[137] R. Shimura, K. Tatsumi, A. Nakamura et al., "Fat accumulation, leptin, and hypercapnia in obstructive sleep apnea-hypopnea syndrome," Chest, vol. 127, no. 2, pp. 543-549, 2005.
[138] K. Shimizu, T. Nakamura, A. Niimi et al., "Plasma leptin levels and cardiac sympathetic function in patients with obstructive sleep apnoea-hypopnoea syndrome," Thorax, vol. 57, no. 5, pp. 429-434, 2002.

[139] C. Çuhadaroğlu, A. Utkusavaş, L. Öztürk, S. Salman, and T. Ece, "Effects of nasal CPAP treatment on insulin resistance, lipid profile, and plasma leptin in sleep apnea," Lung, vol. 187, no. 2, pp. 75-81, 2009.

[140] S. Snitker, R. E. Pratley, M. Nicolson, P. A. Tataranni, and E. Ravussin, "Relationship between muscle sympathetic nerve activity and plasma leptin concentration," Obesity Research, vol. 5, no. 4, pp. 338-340, 1997.

[141] B. Brooks, P. A. Cistulli, M. Borkman et al., "Obstructive sleep apnea in obese noninsulin-dependent diabetic patients: effect of continuous positive airway pressure treatment on insulin responsiveness," Journal of Clinical Endocrinology and Metabolism, vol. 79, no. 6, pp. 1681-1685, 1994.

[142] L. Öztürk, M. Ünal, L. Tamer, and F. Çelikoğlu, “The association of the severity of obstructive sleep apnea with plasma leptin levels," Archives of Otolaryngology-Head and Neck Surgery, vol. 129, no. 5, pp. 538-540, 2003.

[143] S. Zirlik, T. Hauck, F. S. Fuchs, M. F. Neurath, P. C. Konturek, and I. A. Harsch, "Leptin, obestatin and apelin levels in patients with obstructive sleep apnoea syndrome," Medical Science Monitor, vol. 17, no. 3, pp. CR159-CR164, 2011.

[144] N. Al Lawati, A. Mulgrew, R. Cheema et al., "Pro-atherogenic cytokine profile of patients with suspected obstructive sleep apnea," Sleep and Breathing, vol. 13, no. 4, pp. 391-395, 2009.

[145] F. Kapsimalis, G. Varouchakis, A. Manousaki et al., "Association of sleep apnea severity and obesity with insulin resistance, C-reactive protein, and leptin levels in male patients with obstructive sleep apnea," Lung, vol. 186, no. 4, pp. 209-217, 2008.

[146] M. Macrea, T. Martin, L. Zagrean, Z. Jia, and H. Misra, "Role of leptin as antioxidant in obstructive sleep apnea: an in vitro study using electron paramagnetic resonance method.," Sleep and Breathing, vol. 17, no. 1, pp. 105-110, 2013.

[147] D. K. Oh, T. Ciaraldi, and R. R. Henry, "Adiponectin in health and disease," Diabetes, Obesity and Metabolism, vol. 9, no. 3, pp. 282-289, 2007.

[148] N. Ouchi and K. Walsh, "Adiponectin as an anti-inflammatory factor," Clinica Chimica Acta, vol. 380, no. 1-2, pp. 24-30, 2007.

[149] X. L. Zhang, K. S. Yin, H. Wang, and S. Su, "Serum adiponectin levels in adult male patients with obstructive sleep apnea hypopnea syndrome," Respiration, vol. 73, no. 1, pp. 73-77, 2006.

[150] B. Masserini, P. S. Morpurgo, F. Donadio, C. Baldessari, P. BeckPeccoz, and E. Orsi, "Reduced levels of adiponectin in sleep apnea syndrome," Journal of Endocrinological Investigation, vol. 29, no. 8, pp. 700-705, 2006.

[151] E. Vatansever, E. Surmen-Gur, A. Ursavas, and M. Karadag, "Obstructive sleep apnea causes oxidative damage to plasma lipids and proteins and decreases adiponectin levels," Sleep and Breathing, vol. 15, no. 3, pp. 275-282, 2011.

[152] M. Fasshauer, S. Kralisch, M. Klier et al., "Adiponectin gene expression and secretion is inhibited by interleukin-6 in 3T3-L1 adipocytes," Biochemical and Biophysical Research Communications, vol. 301, no. 4, pp. 1045-1050, 2003.

[153] W. T. McNicholas and M. R. Bonsignore, "Sleep apnoea as an independent risk for cardiovascular disease: current evidence, basic mechanisms and research priorities," European Respiratory Journal, vol. 29, no. 1, pp. 156-178, 2007. 
[154] G. Carneiro, S. M. Togeiro, F. F. Ribeiro-Filho et al., "Continuous positive airway pressure therapy improves hypoadiponectinemia in severe obese men with obstructive sleep apnea without changes in insulin resistance," Metabolic Syndrome and Related Disorders, vol. 7, no. 6, pp. 537-542, 2009.

[155] A. M. J. de Lima, C. M. R. Franco, C. M. M. B. de Castro, A. D. A. Bezerra, L. Ataíde Jr., and A. Halpern, "Effects of nasal continuous positive airway pressure treatment on oxidative stress and adiponectin levels in obese patients with obstructive sleep apnea," Respiration, vol. 79, no. 5, pp. 370-376, 2010.

[156] S. Makino, H. Handa, K. Suzukawa et al., "Obstructive sleep apnoea syndrome, plasma adiponectin levels, and insulin resistance," Clinical Endocrinology, vol. 64, no. 1, pp. 12-19, 2006.

[157] Y. Nakagawa, K. Kishida, S. Kihara, R. Yoshida, T. Funahashi, and I. Shimomura, "Nocturnal falls of adiponectin levels in sleep apnea with abdominal obesity and impact of hypoxia-induced dysregulated adiponectin production in obese murine mesenteric adipose tissue," Journal of Atherosclerosis and Thrombosis, vol. 18, no. 3, pp. 240-247, 2011.

[158] M. S. Jamaluddin, S. M. Weakley, Q. Yao, and C. Chen, "Resistin: functional roles and therapeutic considerations for cardiovascular disease," The British Journal of Pharmacology, vol. 165, no. 3, pp. 622-632, 2012.

[159] I. A. Harsch, C. Koebnick, H. Wallaschofski et al., "Resistin levels in patients with obstructive sleep apnoea syndrome-the link to subclinical inflammation?" Medical Science Monitor, vol. 10, no. 9, pp. CR510-CR515, 2004.

[160] Y. Yamamoto, S. Fujiuchi, M. Hiramatsu et al., "Resistin is closely related to systemic inflammation in obstructive sleep apnea," Respiration, vol. 76, no. 4, pp. 377-385, 2008.

[161] A. F. Krapalis, J. Reiter, F. Machleidt et al., "Ghrelin modulates baroreflex-regulation of sympathetic vasomotor tone in healthy humans," The American Journal of Physiology, vol. 302, no. 11, pp. R1305-R1312, 2012.

[162] I. Kishimoto, T. Tokudome, H. Hosoda, M. Miyazato, and K. Kangawa, "Ghrelin and cardiovascular diseases," Journal of Cardiology, vol. 59, no. 1, pp. 8-13, 2012.

[163] I. A. Harsch, P. C. Konturek, C. Koebnick et al., "Leptin and ghrelin levels in patients with obstructive sleep apnoea: effect of CPAP treatment," European Respiratory Journal, vol. 22, no. 2, pp. 251-257, 2003.

[164] A. M. Li, C. Ng, S. K. Ng et al., "Adipokines in children with obstructive sleep apnea and the effects of treatment," Chest, vol. 137, no. 3, pp. 529-535, 2010.

[165] K. Spruyt, O. S. Capdevila, L. D. Serpero, L. Kheirandish-Gozal, and D. Gozal, "Dietary and physical activity patterns in children with obstructive sleep apnea," Journal of Pediatrics, vol. 156, no. 5, pp. 724.e3-730.e3, 2010.

[166] M. Tsaoussoglou, E. O. Bixler, S. Calhoun, G. P. Chrousos, K. Sauder, and A. N. Vgontzas, "Sleep-disordered breathing in obese children is associated with prevalent excessive daytime sleepiness, inflammation, and metabolic abnormalities," Journal of Clinical Endocrinology and Metabolism, vol. 95, no. 1, pp. 143$150,2010$.

[167] M. Sánchez-De-La-Torre, A. Barceló, J. Piérola et al., "Plasma levels of neuropeptides and metabolic hormones, and sleepiness in obstructive sleep apnea," Respiratory Medicine, vol. 105, no. 12, pp. 1954-1960, 2011.

[168] C. Prugger, J. Wellmann, J. Heidrich, S. Brand-Herrmann, and U. Keil, "Cardiovascular risk factors and mortality in patients with coronary heart disease," European Journal of Epidemiology, vol. 23, no. 11, pp. 731-737, 2008.
[169] S. Mondini and C. Guilleminault, "Abnormal breathing patterns during sleep in diabetes," Annals of Neurology, vol. 17, no. 4, pp. 391-395, 1985.

[170] A. Elmasry, E. Lindberg, C. Berne et al., "Sleep-disordered breathing and glucose metabolism in hypertensive men: a population-based study," Journal of Internal Medicine, vol. 249, no. 2, pp. 153-161, 2001.

[171] S. D. West, D. J. Nicoll, and J. R. Stradling, "Prevalence of obstructive sleep apnoea in men with type 2 diabetes," Thorax, vol. 61, no. 11, pp. 945-950, 2006.

[172] J. H. Ficker, S. H. Dertinger, W. Siegfried et al., "Obstructive sleep apnoea and diabetes mellitus: the role of cardiovascular autonomic neuropathy," European Respiratory Journal, vol. 11, no. 1, pp. 14-19, 1998.

[173] P. Bottini, M. L. Dottorini, M. C. Cordoni, G. Casucci, and C. Tantucci, "Sleep-disordered breathing in nonobese diabetic subjects with autonomic neuropathy," European Respiratory Journal, vol. 22, no. 4, pp. 654-660, 2003.

[174] L. K. Brown, "A waist is a terrible thing to mind: central obesity, the metabolic syndrome, and sleep apnea hypopnea syndrome," Chest, vol. 122, no. 3, pp. 774-778, 2002.

[175] A. N. Vgontzas, E. O. Bixler, and G. P. Chrousos, "Metabolic disturbances in obesity versus sleep apnoea: the importance of visceral obesity and insulin resistance," Journal of Internal Medicine, vol. 254, no. 1, pp. 32-44, 2003.

[176] F. Tassone, F. Lanfranco, L. Gianotti et al., "Obstructive sleep apnoea syndrome impairs insulin sensitivity independently of anthropometric variables," Clinical Endocrinology, vol. 59, no. 3, pp. 374-379, 2003.

[177] N. Cheng, W. Cai, M. Jiang, and S. Wu, "Effect of hypoxia on blood glucose, hormones, and insulin receptor functions in newborn calves," Pediatric Research, vol. 41, no. 6, pp. 852-856, 1997.

[178] J. Li, M. Bosch-Marce, A. Nanayakkara et al., "Altered metabolic responses to intermittent hypoxia in mice with partial deficiency of hypoxia-inducible factor-1 $\alpha$," Physiological Genomics, vol. 25, no. 3, pp. 450-457, 2006.

[179] V. Y. Polotsky, J. Li, N. M. Punjabi et al., "Intermittent hypoxia increases insulin resistance in genetically obese mice," Journal of Physiology, vol. 552, no. 1, pp. 253-264, 2003.

[180] B. Braun, P. B. Rock, S. Zamudio et al., "Women at altitude: short-term exposure to hypoxia and/or $\alpha 1$-adrenergic blockade reduces insulin sensitivity," Journal of Applied Physiology, vol. 91, no. 2, pp. 623-631, 2001.

[181] M. Gasa, N. Salord, A. M. Fortuna et al., "Obstructive sleep apnoea and metabolic impairment in severe obesity," European Respiratory Journal, vol. 38, no. 5, pp. 1089-1097, 2011.

[182] N. McArdle, D. Hillman, L. Beilin, and G. Watts, "Metabolic risk factors for vascular disease in obstructive sleep apnea: a matched controlled study," The American Journal of Respiratory and Critical Care Medicine, vol. 175, no. 2, pp. 190-195, 2007.

[183] H. E. Resnick, K. Jones, G. Ruotolo et al., "Insulin resistance, the metabolic syndrome, and risk of incident cardiovascular disease in nondiabetic American Indians: the strong heart study," Diabetes Care, vol. 26, no. 3, pp. 861-867, 2003.

[184] L. Piemonti, G. Calori, A. Mercalli et al., "Fasting plasma leptin, tumor necrosis factor- $\alpha$ receptor 2 , and monocyte chemoattracting protein 1 concentration in a population of glucosetolerant and glucose-intolerant women impact on cardiovascular mortality," Diabetes Care, vol. 26, no. 10, pp. 2883-2889, 2003. 
[185] M. Hayashi, K. Fujimoto, K. Urushibata, A. Takamizawa, O. Kinoshita, and K. Kubo, "Hypoxia-sensitive molecules may modulate the development of atherosclerosis in sleep apnoea syndrome," Respirology, vol. 11, no. 1, pp. 24-31, 2006.

[186] J. A. Batsis, R. E. Nieto-Martinez, and F. Lopez-Jimenez, "Metabolic syndrome: from global epidemiology to individualized medicine," Clinical Pharmacology and Therapeutics, vol. 82, no. 5, pp. 509-524, 2007.

[187] T. A. Welborn, A. Breckenridge, A. H. Rubinstein, C. T. Dollery, and T. R. Fraser, "Serum-insulin in essential hypertension and in peripheral vascular disease," The Lancet, vol. 1, no. 7451, pp. 1336-1337, 1966.

[188] G. Reaven, "Metabolic syndrome: pathophysiology and implications for management of cardiovascular disease," Circulation, vol. 106, no. 3, pp. 286-288, 2002.

[189] S. M. Grundy, H. B. Brewer Jr., J. I. Cleeman, S. C. Smith Jr., and C. Lenfant, "Definition of metabolic syndrome: report of the national heart, lung, and blood institute/American heart association conference on scientific issues related to definition," Arteriosclerosis, Thrombosis, and Vascular Biology, vol. 24, no. 2, pp. e13-e18, 2004.

[190] M. Ambrosetti, A. M. Lucioni, S. Conti, R. F. Pedretti, and M. Neri, "Metabolic syndrome in obstructive sleep apnea and related cardiovascular risk," Journal of Cardiovascular Medicine, vol. 7, no. 11, pp. 826-829, 2006.

[191] O. K. Basoglu, F. Sarac, S. Sarac, H. Uluer, and C. Yilmaz, "Metabolic syndrome, insulin resistance, fibrinogen, homocysteine, leptin, and C-reactive protein in obese patients with obstructive sleep apnea syndrome," Annals of Thoracic Medicine, vol. 6, no. 3, pp. 120-125, 2011.

[192] A. N. Vgontzas, E. O. Bixler, and G. P. Chrousos, "Sleep apnea is a manifestation of the metabolic syndrome," Sleep Medicine Reviews, vol. 9, no. 3, pp. 211-224, 2005.

[193] A. Gruber, F. Horwood, J. Sithole, N. J. Ali, and I. Idris, "Obstructive sleep apnoea is independently associated with the metabolic syndrome but not insulin resistance state," Cardiovascular Diabetology, vol. 5, article 22, 2006.

[194] J. C. M. Lam, B. Lam, C. Lam et al., "Obstructive sleep apnea and the metabolic syndrome in community-based Chinese adults in Hong Kong," Respiratory Medicine, vol. 100, no. 6, pp. 980-987, 2006.

[195] K. Shina, H. Tomiyama, Y. Takata et al., "Concurrent presence of metabolic syndrome in obstructive sleep apnea syndrome exacerbates the cardiovascular risk: a sleep clinic cohort study," Hypertension Research, vol. 29, no. 6, pp. 433-441, 2006.

[196] M. R. Bonsignore, C. Esquinas, A. Barcelo et al., "Metabolic syndrome, insulin resistance and sleepiness in real-life obstructive sleep apnoea," European Respiratory Journal, vol. 39, no. 5, pp. 1136-1143, 2012.

[197] M. R. Bonsignore and A. Zito, "Metabolic effects of the obstructive sleep apnea syndrome and cardiovascular risk," Archives of Physiology and Biochemistry, vol. 114, no. 4, pp. 255-260, 2008.

[198] P. Lévy, J. Pépin, C. Arnaud, J. Baguet, M. Dematteis, and F. Mach, "Obstructive sleep apnea and atherosclerosis," Progress in Cardiovascular Diseases, vol. 51, no. 5, pp. 400-410, 2009.

[199] M. C. Su, Y. C. Chen, K. T. Huang, C. C. Wang, M. C. Lin, and H. C. Lin, "Association of metabolic factors with highsensitivity C-reactive protein in patients with sleep-disordered breathing," European Archives of Oto-Rhino-Laryngology, pp. 749-754, 2013.

[200] S. K. Sharma, S. Agrawal, D. Damodaran et al., "CPAP for the metabolic syndrome in patients with obstructive sleep apnea,"
The New England Journal of Medicine, vol. 365, no. 24, pp. 22772286, 2011.

[201] A. G. Agustí, "Systemic effects of chronic obstructive pulmonary disease," 2Proceedings of the American Thoracic Society, vol. 2, no. 4, pp. 367-370, 2005.

[202] P. de Lucas-Ramos, J. L. Izquierdo-Alonso, J. M. RodriguezGonzalez Moro, J. F. Frances, P. V. Lozano, and J. M. BellonCano, "Chronic obstructive pulmonary disease as a cardiovascular risk factor. Results of a case-control study (CONSISTE study)," International Journal of Chronic Obstructive Pulmonary Disease, pp. 679-686, 2012.

[203] J. D. Maclay, D. A. McAllister, S. Johnston et al., "Increased platelet activation in patients with stable and acute exacerbation of COPD," Thorax, vol. 66, no. 9, pp. 769-774, 2011.

[204] G. Cella, A. Sbarai, G. Mazzaro et al., "Plasma markers of endothelial dysfunction in chronic obstructive pulmonary disease," Clinical and Applied Thrombosis/Hemostasis, vol. 7, no. 3, pp. 205-208, 2001.

[205] L. Moro, C. Pedone, S. Scarlata, V. Malafarina, F. Fimognari, and R. Antonelli-Incalzi, "Endothelial dysfunction in chronic obstructive pulmonary disease," Angiology, vol. 59, no. 3, pp. 357-364, 2008.

[206] K. Nakanishi, Y. Takeda, S. Tetsumoto et al., "Involvement of endothelial apoptosis underlying chronic obstructive pulmonary disease-like phenotype in adiponectin-null mice: implications for therapy," The American Journal of Respiratory and Critical Care Medicine, vol. 183, no. 9, pp. 1164-1175, 2011.

[207] C. Minet, I. Vivodtzev, R. Tamisier et al., "Reduced six-minute walking distance, high fat-free-mass index and hypercapnia are associated with endothelial dysfunction in COPD," Respiratory Physiology and Neurobiology, vol. 183, no. 2, pp. 128-134, 2012.

[208] N. Takabatake, H. Nakamura, S. Abe et al., "The relationship between chronic hypoxemia and activation of the tumor necrosis factor- $\alpha$ system in patients with chronic obstructive pulmonary disease," The American Journal of Respiratory and Critical Care Medicine, vol. 161, no. 4 I, pp. 1179-1184, 2000.

[209] N. L. Mills, J. J. Miller, A. Anand et al., "Increased arterial stiffness in patients with chronic obstructive pulmonary disease: a mechanism for increased cardiovascular risk," Thorax, vol. 63, no. 4, pp. 306-311, 2008.

[210] S. Andreas, S. D. Anker, P. D. Scanlon, and V. K. Somers, "Neurohumoral activation as a link to systemic manifestations of chronic lung disease," Chest, vol. 128, no. 5, pp. 3618-3624, 2005.

[211] T. Raupach, F. Bahr, P. Herrmann et al., "Slow breathing reduces sympathoexcitation in COPD," European Respiratory Journal, vol. 32, no. 2, pp. 387-392, 2008.

[212] S. Heindl, M. Lehnert, C. Criée, G. Hasenfuss, and S. Andreas, "Marked sympathetic activation in patients with chronic respiratory failure," The American Journal of Respiratory and Critical Care Medicine, vol. 164, no. 4, pp. 597-601, 2001.

[213] D. C. Flenley, "Sleep in chronic obstructive lung disease," Clinics in Chest Medicine, vol. 6, no. 4, pp. 651-661, 1985.

[214] A. Chaouat, E. Weitzenblum, J. Krieger, M. Oswald, and R. Kessler, "Pulmonary hemodynamics in the obstructive sleep apnea syndrome results in 220 consecutive patients," Chest, vol. 109, no. 2, pp. 380-386, 1996.

[215] I. Hawrylkiewicz, P. Sliwinski, D. Gorecka, R. Plywaczewski, and J. Zielinski, "Pulmonary haemodynamics in patients with OSAS or an overlap syndrome," Monaldi Archives for Chest Disease, vol. 61, pp. 148-152, 2004. 
[216] W. MacNee, J. Maclay, and D. McAllister, "Cardiovascular injury and repair in chronic obstructive pulmonary disease," Proceedings of the American Thoracic Society, vol. 5, no. 8, pp. 824-833, 2008.

[217] G. S. Gilmartin, R. Tamisier, M. Curley, and J. W. Weiss, "Ventilatory, hemodynamic, sympathetic nervous system, and vascular reactivity changes after recurrent nocturnal sustained hypoxia in humans," The American Journal of Physiology, vol. 295, no. 2, pp. H778-H785, 2008.

[218] K. Shiina, H. Tomiyama, Y. Takata et al., "Overlap syndrome: additive effects of COPD on the cardiovascular damages in patients with OSA," Respiratory Medicine, vol. 106, no. 9, pp. 1335-1341, 2012.

[219] J. M. Marin, J. B. Soriano, S. J. Carrizo, A. Boldova, and B. R. Celli, "Outcomes in patients with chronic obstructive pulmonary disease and obstructive sleep apnea: the overlap syndrome," The American Journal of Respiratory and Critical Care Medicine, vol. 182, no. 3, pp. 325-331, 2010.

[220] C. Pronzato, "Chronic obstructive pulmonary disease and obstructive sleep apnea. Association, consequences and treatment," Monaldi Archives for Chest Disease, vol. 73, no. 4, pp. 155161, 2010.

[221] S. Nural, E. Gunay, B. Halici, S. Celik, and M. Unlu, "Inflammatory processes and effects of continuous positive airway pressure (CPAP) in overlap syndrome," Inflammation, vol. 36, no. 1, pp. 66-74, 2013. 


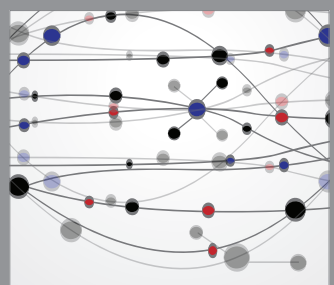

The Scientific World Journal
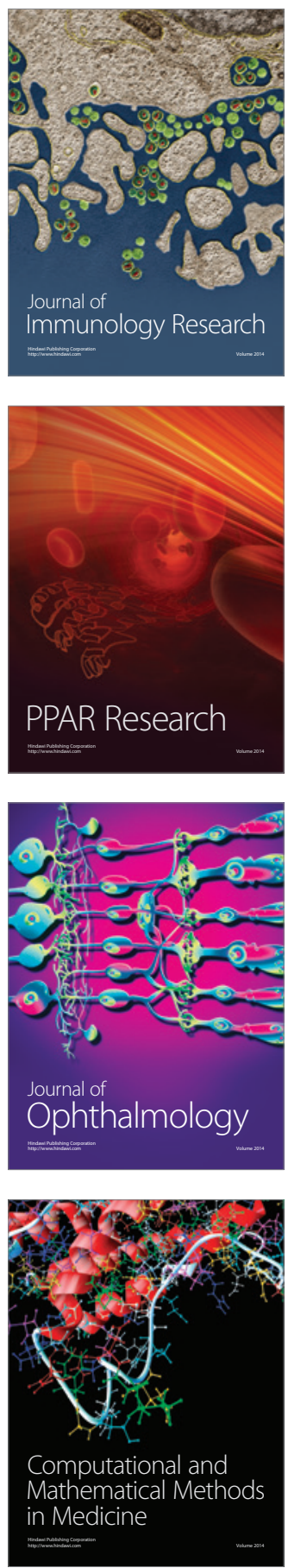

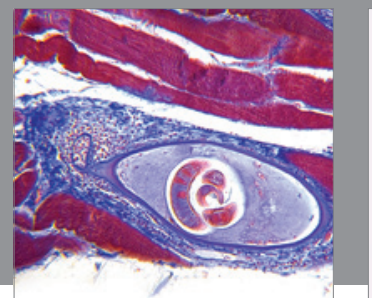

Gastroenterology

Research and Practice
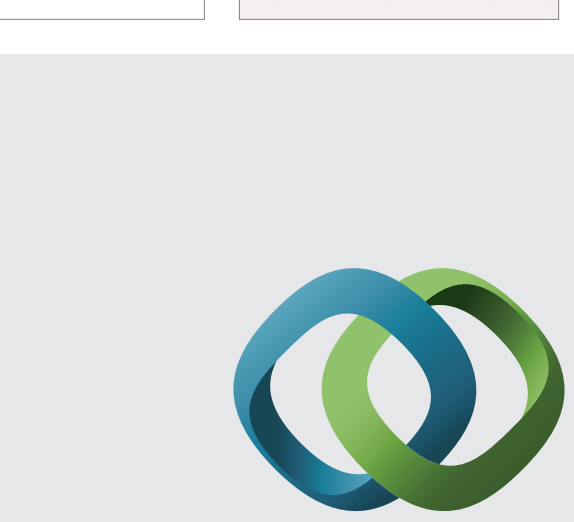

\section{Hindawi}

Submit your manuscripts at

http://www.hindawi.com
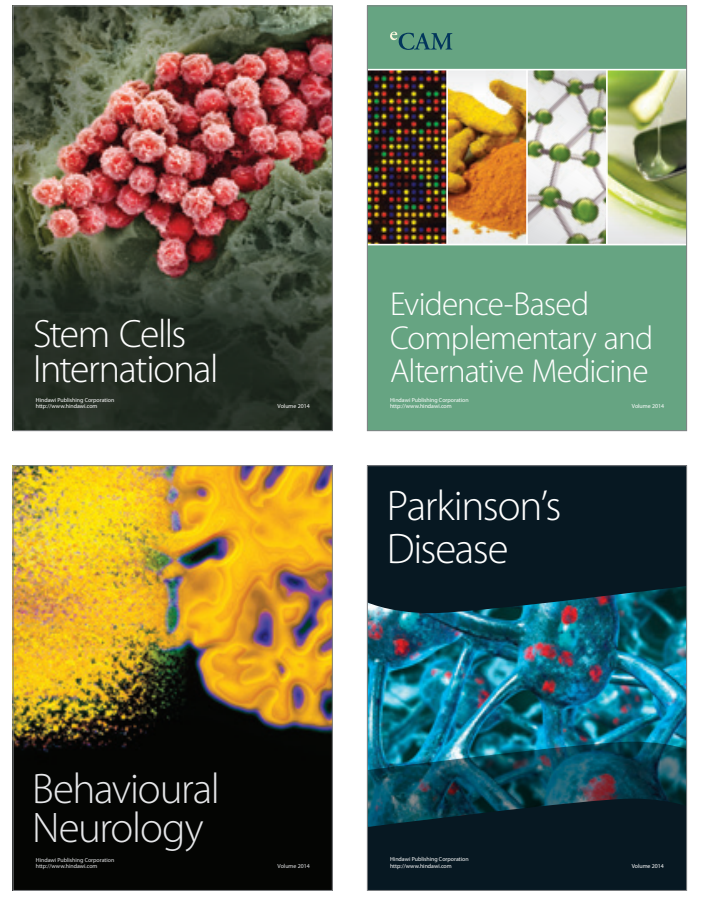
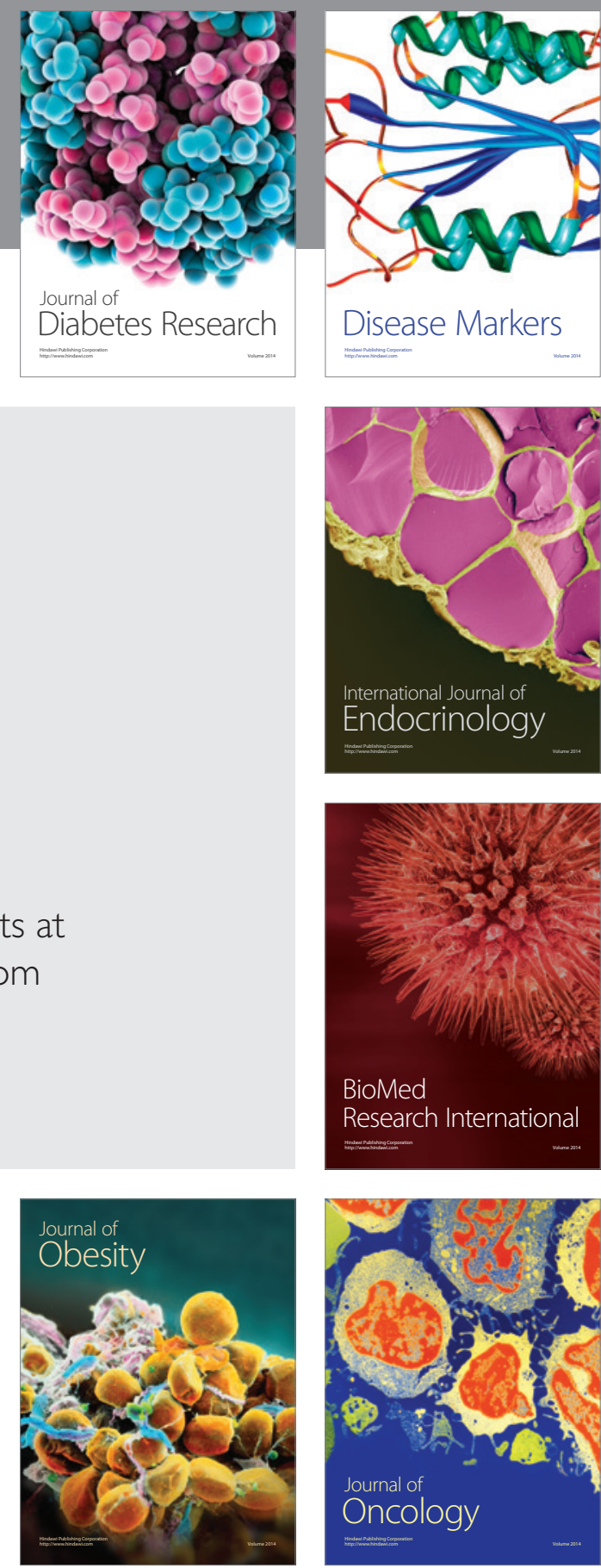

Disease Markers
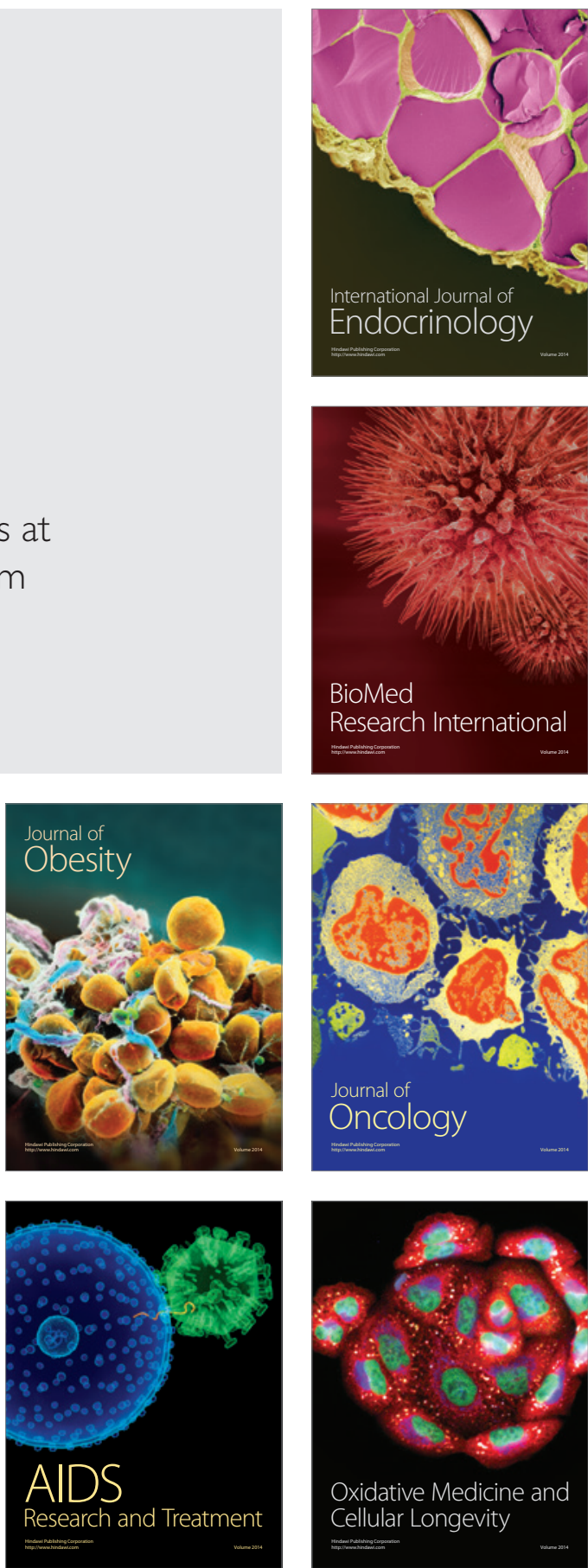